$$
\text { Y-12 }
$$

\section{OAK RIDGE}

\section{$\mathrm{Y}-12$}

PLANT

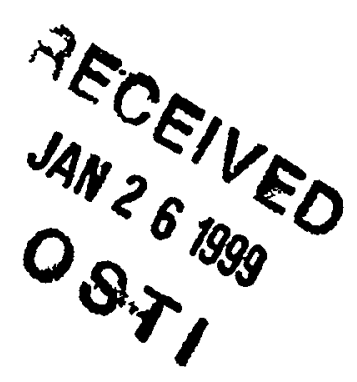

\title{
NWIS MEASUREMENTS FOR URANIUM METAL ANNULAR CASTINGS
}

\author{
J. K. Mattingly \\ T. E. Valentine \\ J. T. Mihalczo
}

Nuclear Materials Management and

Storage Program Office

March 13, 1998

MANAGED BY

LOCKHEED MARTIN ENERGY SYSTEMS, INC. FOR THE UNITED STATES DEPARTMENT OF ENERGY
Prepared by the

Oak Ridge Y-12 Plant

Oak Ridge, Tennessee 37831 managed by

Lockheed Martin Energy Systems, Inc. for the U.S. DEPARTMENT OF ENERGY under contract DE-AC05-84OR21400 


\section{DISCLAIMER}

Portions of this document may be illegible in electronic image products. Images are produced from the best available original document. 


\section{DISCLAIMER}

This report was prepared as an account of work sponsored by an agency of the United States government. Neither the United States Government nor any agency thereof, nor any of their employees, makes any warranty, express or implied, or assumes any legal liability or responsibility for the accuracy, completeness, or usefulness of any information, apparatus, product, or process disclosed, or represents that its use would not infringe privately owned rights. Reference herein to any specific commercial product, process, or service by trade name, trademark, manufacturer, or otherwise, does not necessarily constitute or imply its endorsement, recommendation, or favoring by the United States Government or any agency thereof. The views and opinions of authors expressed herein do not necessarily state or reflect those of the United States Government or any agency thereof.

\section{COPYRIGHT NOTICE}

The submitted manuscript has been authored by a contractor of the U.S. Government under contract DE-AC05-84OR21400. Accordingly, the U.S. Government retains a paid-up, nonexclusive, irrevocable, worldwide license to publish or reproduce the published form of this contribution, prepare derivative works, distribute copies to the public, and perform publicly and display publicly, or allow others to do so, for U.S.

Government purposes. 
T. E. Valentine

J. K. Mattingly

J. T. Mihalczo

Oak Ridge National Laboratory*

P.O. Box 2008

Oak Ridge, Tennessee 37831

(423) $574-5577$

March 13, 1998

- Managed by Lockheed Martin Energy Research Corporation for the U.S. Department of Energy under contract DE-AC05-96OR22464I 


\section{Contents}

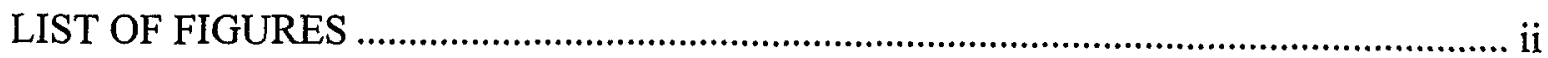

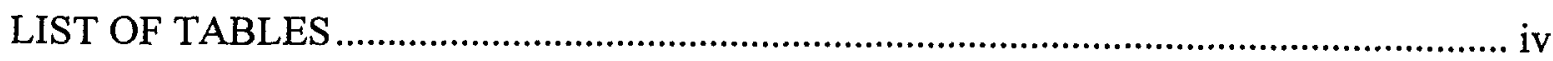

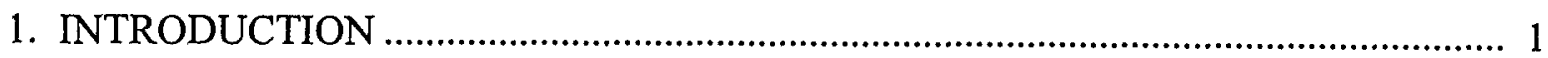

2. ${ }^{252} \mathrm{CF}$-SOURCE-DRIVEN NOISE ANALYSIS MEASUREMENT............................... 1

2.1 Auto-and Cross-correlation Functions .................................................................. 2

2.2 Auto and Cross Power Spectral Densities .......................................................... 5

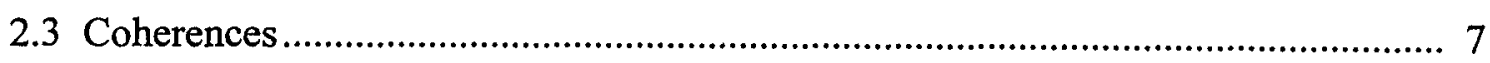

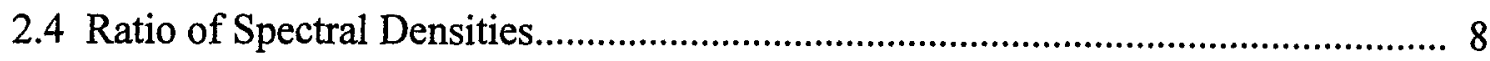

2.5 Count Probability Distribution Function ............................................................... 9

3. NWIS PROCESSOR AND ELECTRONICS............................................................13

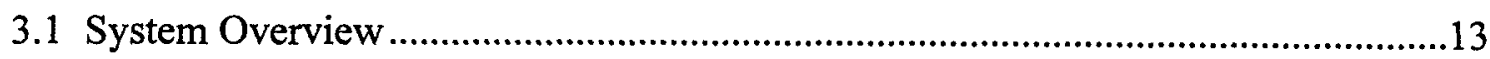

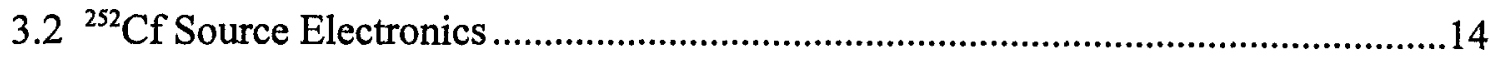

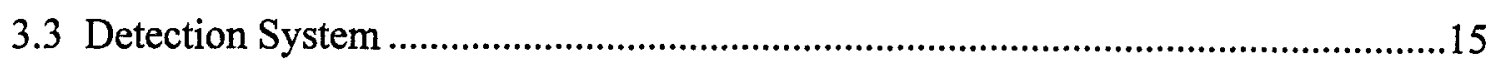

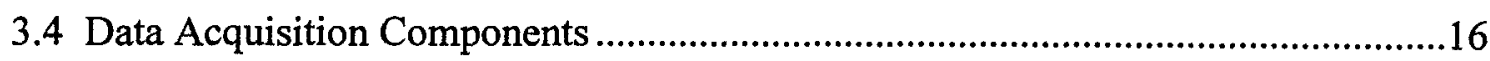

4. DESCRIPTION OF URANIUM METAL CASTINGS …..........................................17

5. DESCRIPTION OF MEASUREMENTS WITH CASTINGS OF VARYING

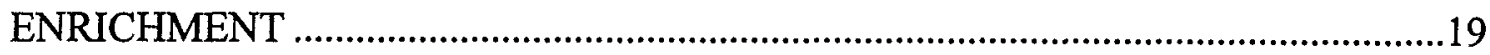

6. RESULTS OF MEASUREMENTS WITH CASTINGS OF VARYING

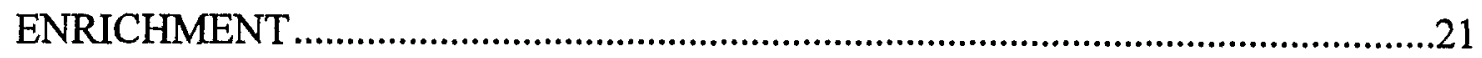

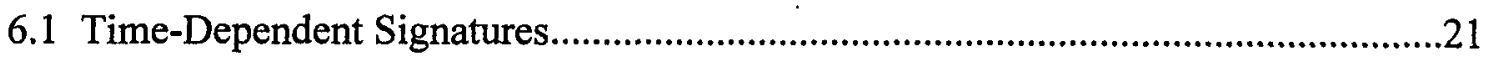

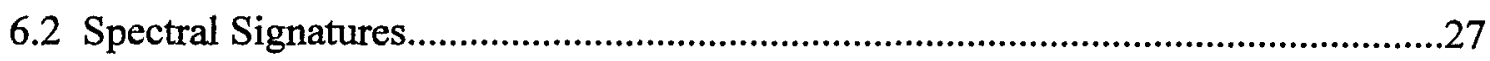

6.3 Count Probability Distribution Function ...................................................................3

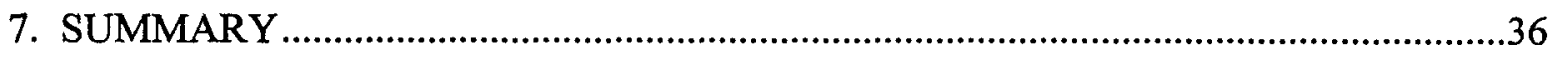

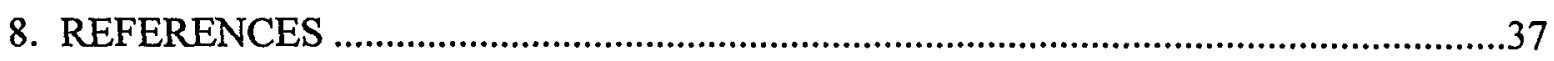




\section{List of Figures}

Fig. 2.1. Configuration for noise measurement................................................................ 2

Fig. 2.2 Source autocorrelation function ...................................................................... 3

Fig. 2.3. Detector autocorrelation function .................................................................. 4

Fig. 2.4. Source-detector cross-correlation function ........................................................... 4

Fig. 2.5. Detector-detector cross-correlation function.......................................................... 5

Fig. 2.6. Auto power spectral density (APSD) of detector channel 2 ................................ 6

Fig. 2.7. Cross power spectral density between detector channel 2 and the source channel (1) as a function of frequency ................................................................. 6

Fig. 2.8. Coherence between a detection channel and the ${ }^{252} \mathrm{Cf}$ source as a function of frequency .................................................................................................... 7

Fig. 2.9. Coherence between two detection channels as a function of frequency ............... 8

Fig. 2.10. Ratio of spectral densities as a function of frequency ......................................... 9

Fig. 2.11. Gate multiplicities for the source ionization chamber channel.............................10

Fig. 2.12. Gate multiplicities for a single detector channel (2) .............................................10

Fig. 2.13. Combined gate multiplicity for all detector channels ...........................................11

Fig. 2.14. Ratios of n-tuplets to singles as a function of doublets to singlets for a uranium casting with varying moderator thickness ..................................................12

Fig. 3.1 NWIS signature acquisition with cart-portable system at the Y-12 Plant (1996).

Fig. 3.2. Block diagram of nuclear detection electronic components .................................14

Fig. 3.3. ${ }^{252} \mathrm{Cf}$ source ionization chamber and amplifier.....................................................15

Fig. 3.4. Typical source-detector configuration for measurements with unmoderated high enriched uranium metal castings in containers ...............................................16

Fig. 3.5. DCC electronic board .......................................................................................17 


\section{List of Figures (Cont'd.)}

Fig. 4.1. High enriched uranium metal annular casting ........................................................17

Fig. 4.2. Uranium metal casting in steel container..............................................................18

Fig. 5.1. Sketch of top view of measurement configuration with annular casting.............19

Fig. 5.2. Sketch of side view of measurement configuration with annular casting.............20

Fig. 6.1. Detector autocorrelation function [2,2] for uranium metal castings ....................22

Fig. 6.2. Integral of detector autocorrelation function [2,2]) for uranium metal castings as a function of ${ }^{235} \mathrm{U}$ mass.......................................................................23

Fig. 6.3. Source-detector cross-correlation $[1,2]$ for uranium metal castings .....................23

Fig. 6.4. Integral of source-detector cross-correlation [1,2] as a function of ${ }^{235} \mathrm{U}$ mass for uranium metal castings .......................................................................25

Fig. 6.5. Detector-detector cross-correlation [2,3]) for uranium metal castings ..................25

Fig. 6.6. Integral of detector-detector cross-correlation $[2,3]$ vs ${ }^{235} \mathrm{U}$ mass ........................26

Fig. 6.7. Detector auto power spectral densities [2,2] as a function of frequency for annular uranium metal castings..........................................................................27

Fig. 6.8. Source-detector cross power spectral densities [1,2] as a function of frequency for annular uranium metal castings........................................................28

Fig. 6.9. Detector-detector cross power spectral densities [2,3] as a function of frequency for annular uranium metal castings.

Fig. 6.10. Source-detector coherence $[1,2]$ as a function of frequency for annular uranium metal castings of varying enrichment of ${ }^{235} \mathrm{U}$ mass 30

Fig. 6.11. Source-detector coherence $[1,2]$ vs ${ }^{235} \mathrm{U}$ mass of annular metal castings...............31

Fig. 6.12. Detector-detector coherence function [2,3]) for uranium metal castings..............32

Fig. 6.13. Extrapolated low-frequency detector-detector coherence $[2,3]$ vs ${ }^{235} \mathrm{U}$ mass for uranium metal casting 


\section{List of Tables}

Table 2.1. Ratios of combined count probability distributions for all detectors for an HEU-metal casting with 3-in. of moderator.

Table 4.1. Annular uranium metal castings

Table 6.1. Integral of detector autocorrelation functions and sensitivity coefficients for annular uranium metal castings

Table 6.2. Integral of source-detector correlation functions and sensitivity coefficients for annular uranium metal castings.

Table 6.3. Integral of detector-detector cross-correlation functions and sensitivity coefficients for annular uranium metal castings

Table 6.4. Extrapolated low-frequency source-detector coherence values for annular uranium metal castings

Table 6.5. Extrapolated low-frequency coherence values for annular uranium metal cylinders

Table 6.6. Measured count probability distribution values and average counts per block for annular uranium metal castings

Table 6.7. . Count moments and sensitivity coefficients for annular uranium metal castings.

Table 6.8. Difference between measured count probability distribution values and Poisson-distributed values 


\section{INTRODUCTION}

This report describes measurements performed with annular uranium metal castings of different enrichments to investigate the use of ${ }^{252} \mathrm{Cf}$-source-driven noise analysis measurements ${ }^{1}$ as a means to quantify the amount of special nuclear material (SNM) in the casting. This work in FY 97 was sponsored by the Oak Ridge Y-12 Plant and the DOE Office of Technology Development Programs. Previous measurements ${ }^{2}$ and calculational studies ${ }^{3}$ have shown that many of the signatures obtained from the source-driven measurement are very sensitive to fissile mass. Measurements were performed to assess the applicability of this method to standard annular uranium metal castings at the Oak Ridge Y-12 plant under verification by the International Atomic Energy Agency (IAEA) using the Nuclear Weapons Identification System (NWIS) processor ${ }^{4}$. Before the measurements with different enrichments, a limited study of source-detector-casting moderator configurations was performed to enhance the correlated information. These configurations consisted of a casting with no reflector and with various thicknesses of polyethylene reflectors up to $10.16 \mathrm{~cm}$ in $2.54 \mathrm{~cm}$ steps. The polyethylene moderator thickness of $7.62 \mathrm{~cm}$ was used for measurements with castings of different enrichments reported here. The sensitivity of the measured parameters to fissile mass was investigated using four castings each with a different enrichment. The high sensitivity of this measurement method to fissile mass and to other material and configurations provides some advantages over existing safeguards methods.

The report is organized in the following manner. A detailed description of the measurement methodology is provided along with a description of the NWIS hardware used to perform the measurements. Preliminary results are presented for a variety of time-and frequency-analysis signatures that demonstrates the sensitivity of the measured parameter to fissile mass. However, these preliminary results do not represent an optimized measurement configuration but are intended to demonstrate possible applications of this method. The results are summarized and recommendations for future work are provided.

\section{2. ${ }^{252}$ CF-SOURCE-DRIVEN NOISE ANALYSIS MEASUREMENT}

The ${ }^{252} \mathrm{Cf}$-source-driven noise analysis method evolved as a combination of randomly pulsed neutron measurements ${ }^{5}$ and Rossi- $\alpha$ measurements ${ }^{6}$. The ${ }^{252} \mathrm{Cf}$ source is used to initiate events in the fissile material and the subsequent emission of neutrons and gamma rays from the fissile system are measured with two or more detectors. A typical configuration for this measurement is shown in Fig. 2.1. The ${ }^{252} \mathrm{Cf}$ source is contained within an ionization chamber and provides a pulse for each spontaneous fission event. The source ionization chamber is typically designated as detector $\# I$ and the radiation detectors are designated as $\# 2, \# 3$, \#4, etc. The pulses from the source and detectors are acquired over time into time bins, typically 512 or 1024 time bins. The source and detector signals are then correlated with each other to obtain a wide variety of time and frequency analysis parameters. The NWIS processor performs the correlations in the time domain and uses the fast Fourier transform to obtain the frequency analysis parameters. In addition, the NWIS processor acquires the number of times 
m pulses occur in a time interval or block of data. From these values, the moments or reduced moments of the count events as well as the Feynman variance can be obtained. A detailed description of the NWIS processor is provided in section 3. The correlation of the source with the detector is equivalent to the pulsed neutron measurement or differential dieaway with an accelerator. The correlation of a detector with itself is termed a detector autocorrelation and is equivalent to the single detector Rossi- $\alpha$ measurement. The correlation between detectors is equivalent to the two detector Rossi- $\alpha$ measurement. By Fourier transforming the correlation functions one obtains the frequency analysis parameters.

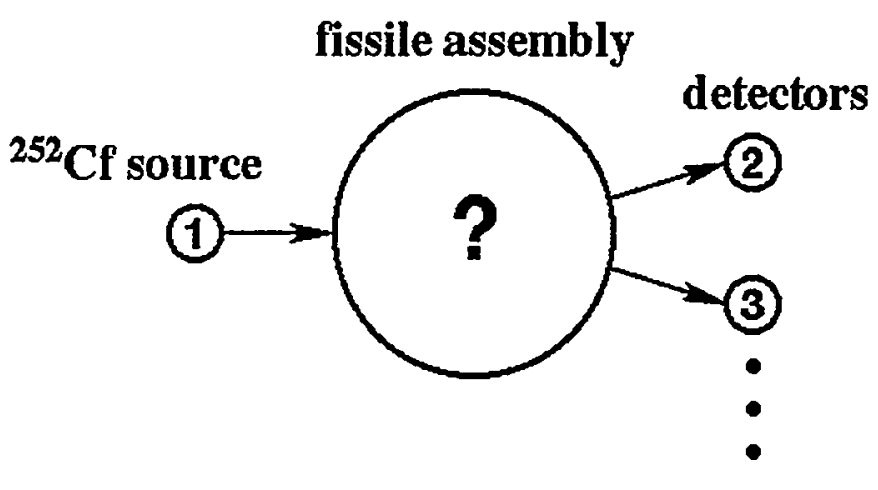

Fig. 2.1. Configuration for noise measurement.

\subsection{AUTO-AND CROSS-CORRELATION FUNCTIONS}

The signatures obtained from the described measurement configuration involve all twochannel combinations (i.e., $1 \& 2,1 \& 3,2 \& 3$, etc.) including signatures that correlate an individual signal with itself (i.e., $1 \& 1,2 \& 2,3 \& 3$, etc.). These signatures are acquired in the time domain using the NWIS processor. In the time domain the correlations between different signals are termed cross-correlation functions and those correlations involving a single signal are termed autocorrelation functions. Likewise, in the frequency domain, the correlation signatures between different signals are termed cross-power spectral densities (CPSDs), while those involving the same signal twice are termed autopower spectral densities (APSDs). The correlation signatures and frequency signatures have the following properties.

The autocorrelation functions are denoted as $R_{11}, R_{22}, R_{33}$, etc. The autocorrelation of the source, $R_{11}$, is proportional to the source strength while the detector autocorrelation functions $R_{22}, R_{33}$, etc. are equivalent to the single detector Rossi- $\alpha$ measurement. A plot of the source autocorrelation function is given in Fig. 2.2 This plot has three unique features: a delta function at time zero, a time period in which there are no correlated counts, and a region of constant correlated counts. The delta function at lag zero occurs because the individual spontaneous fission events of the ${ }^{252} \mathrm{Cf}$ source are independent of each other which means that correlations can only occur at zero lag. The time width of the region in which there are no 
correlated counts is the dead time for the source signal processing electronics. ${ }^{7}$ When a pulse is received from the source signal, the processor cannot acquire another pulse before the end of the dead time period. The region in which the source correlation function is a constant result because of the average source spontaneous fission rate. Although the spontaneous fission events are not related, an "accidental" correlation will occur if more than one source fission occurs in the time period of the data block. An example of the detector autocorrelation function for random counting is provided in Fig. 2.3 and exhibits some of the same features as the source autocorrelation function. The detector autocorrelation function should exhibit an exponential decrease in the region 0 to $20 \mathrm{~ns}$, but does not exhibit an exponential decay due to the random source used for this data acquisition. The detector autocorrelation functions for fissile systems are dependent on source induced and inherent fission events and background radiation. The source-detector cross-correlations $R_{12}, R_{13}$, etc. are equivalent to the pulsed neutron measurement (differential diewaway). and are mainly dependent on the induced fission rate in and transmission rate through the system. An example of the sourcedetector cross-correlation function is given in Figure 2.4. The source-detector correlation function consists of two major components: a peak due to directly transmitted gamma rays from the ${ }^{252} \mathrm{Cf}$ source and a peak due to scattered gamma rays, transmitted and scattered neutrons, and prompt neutrons and gamma rays from fission. The accidental correlations are the result of the average counting rate of the source and detectors per time interval. The between-detector cross-correlation functions are denoted as $R_{23}, R_{24}$, etc. and indicate the amount of correlated information between the two detectors. The between-detector correlations depend on both source-induced and inherent fission occurring in the system. An example of the between-detector correlation function is given in Figure 2.5. This function is essentially symmetric as a function of time. The peak at time time 0 is

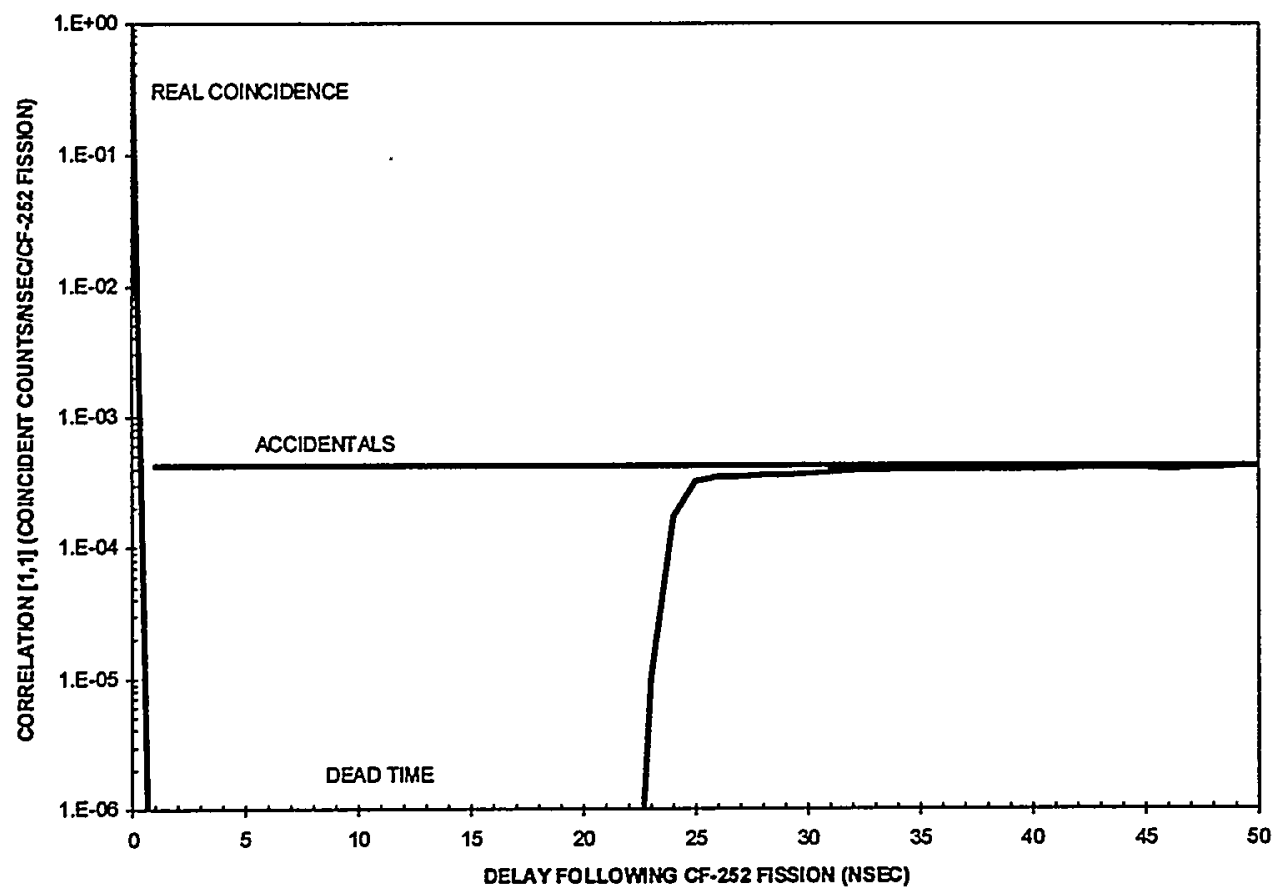

Fig. 2.2. Source autocorrelation function. 


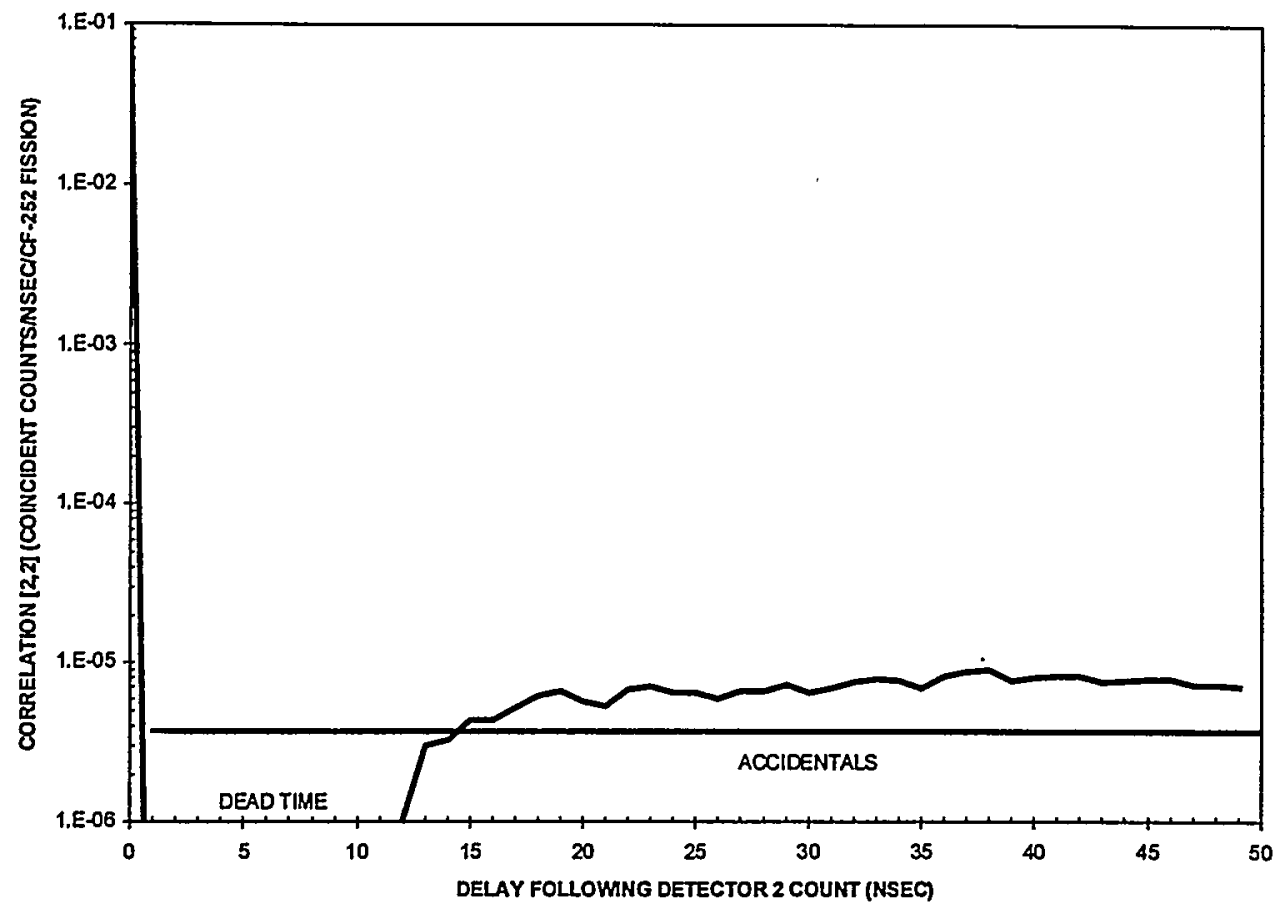

Fig. 2.3. Detector autocorrelation function.

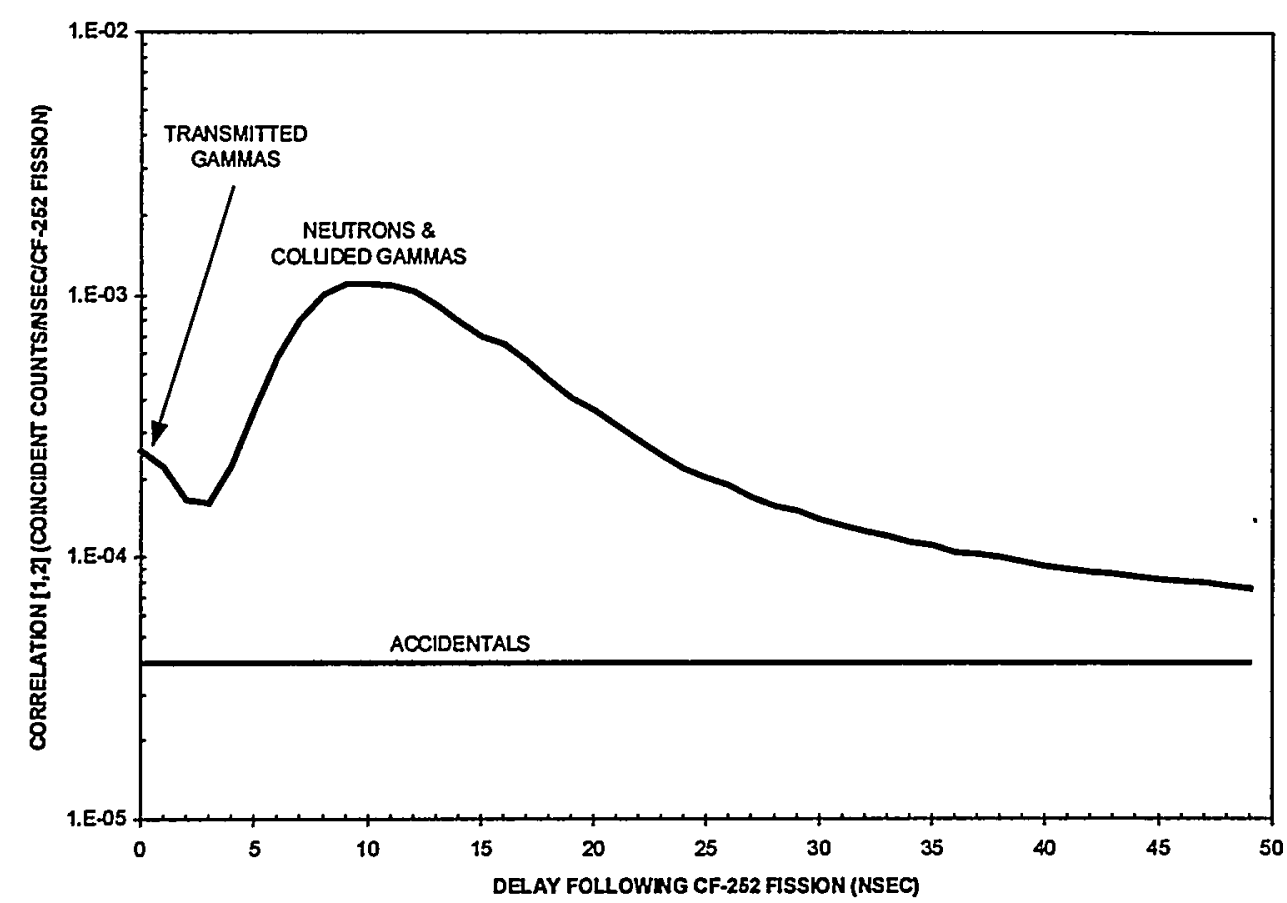

Fig. 2.4. Source-detector cross-correlation function. 


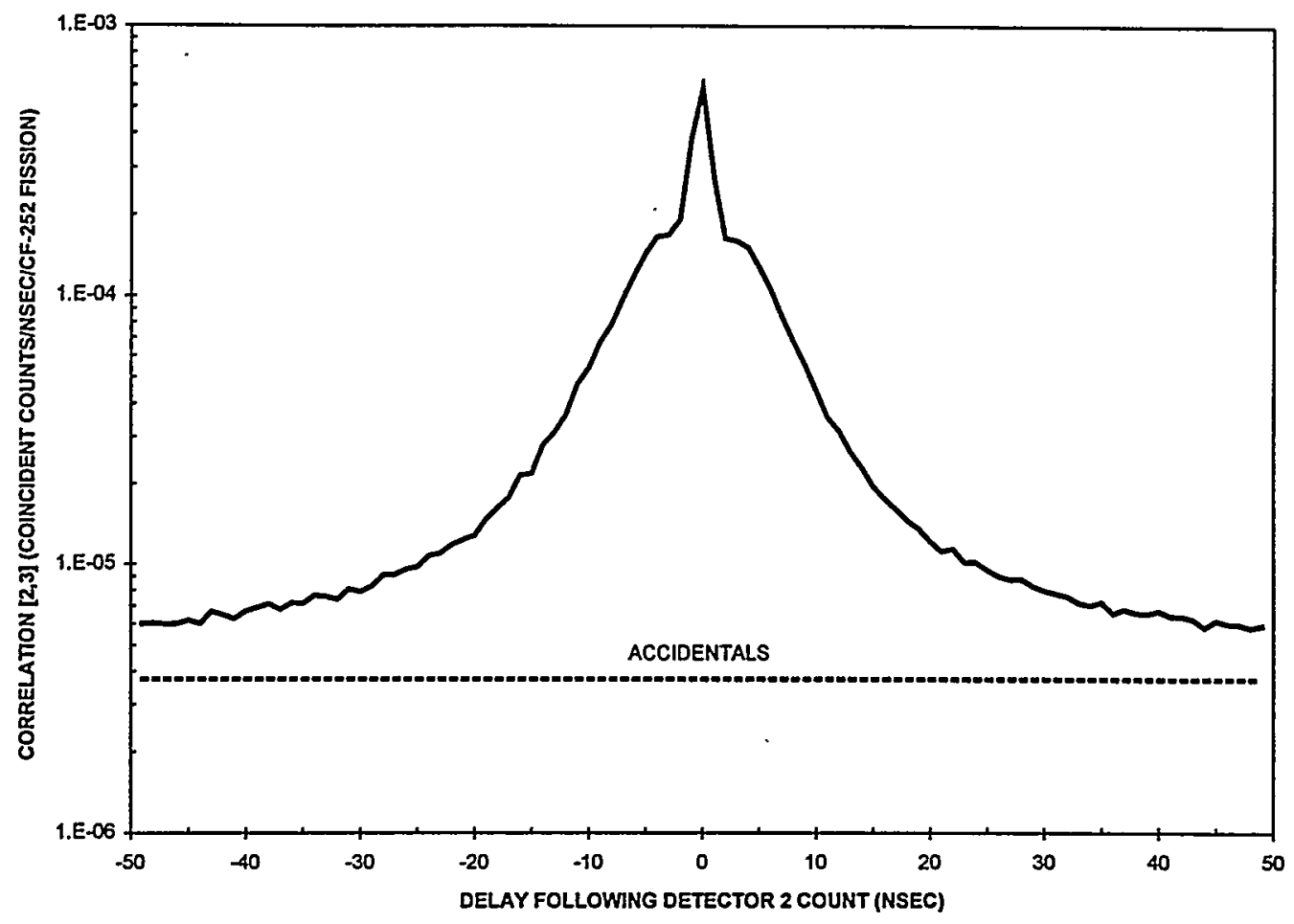

Fig. 2.5. Detector-detector cross-correlation function.

mainly the result of coincident gamma rays from fission in both detectors. Beyond $\sim 5$ ns the time dependence can exhibit an exponential decrease if the source activity is high enough. The accidental correlations are the result of the average count rate of the detectors per time interval. The detector autocorrelation functions, the source-detector cross-correlation functions, and the between-detector cross-correlation functions are all "differential" die-away measurements that are used to determine the decay of prompt neutron fission chains in the system. This prompt time decay can be obscured if the accidental correlations are high; consequently, frequency analysis methods were investigated to overcome this difficulty. The Fourier transforms of the autocorrelation functions are termed autopower spectral densities while the Fourier transforms of the cross-correlation functions are termed cross-power spectral densities.

\subsection{AUTO AND CROSS POWER SPECTRAL DENSITIES}

The source auto spectrum $G_{11}$ is simply a measure of the fission source strength. The detector auto power spectral densities $G_{22}, G_{33}$, etc. are a measure of the source-induced and inherent fission rate of the system and the background rate and are proportional to the detector count rate. The source-detector cross-spectra $G_{12}, G_{13}$, etc. are a measure of counting events in the detectors correlated with fission events in the source. Consequently, the source-detector cross-spectra indicates the amount of source-induced fission occurring in the system. The detector cross-spectra $G_{23}, G_{24}$, etc. are a measure of the events in one 
detector correlated with events in another detector, so their magnitudes indicate the amount of both source-induced and inherent fission occurring in the system analyzed. Plots of $G_{22}$ and $\mathrm{G}_{12}$ are given in Figs. 2.6 and 2.7.

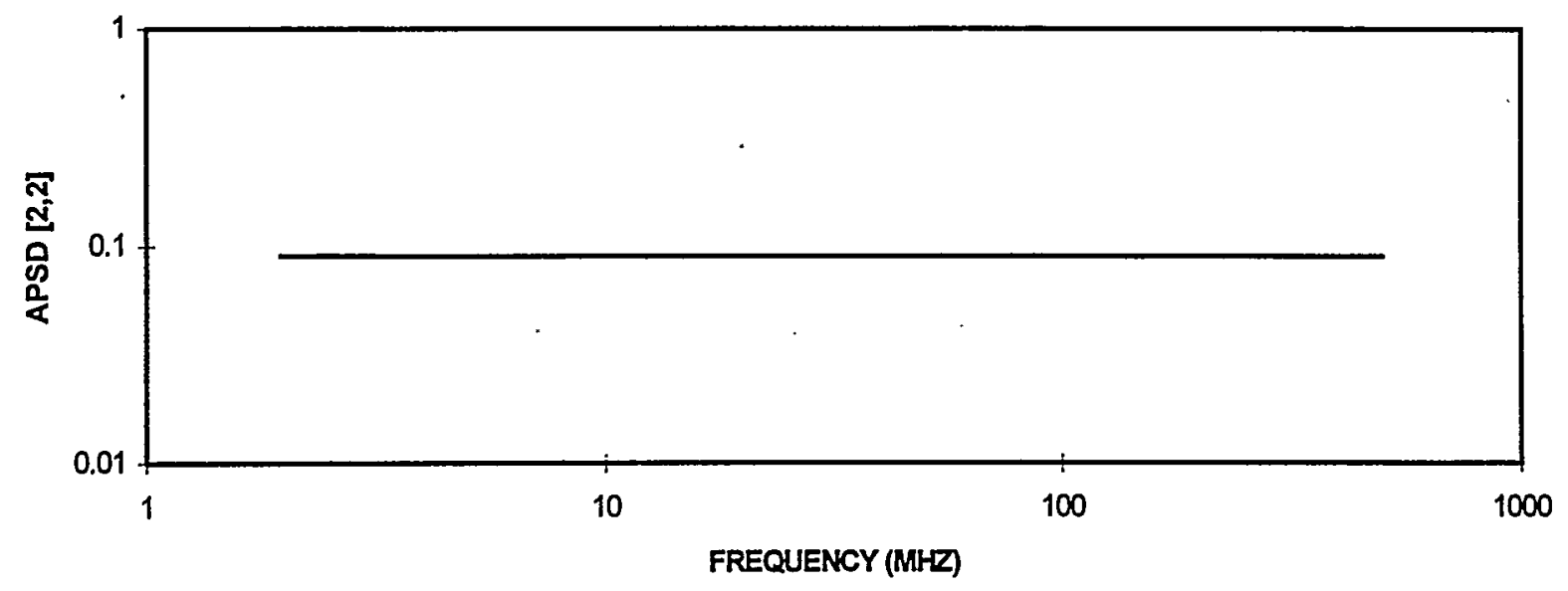

Fig. 2.6. Auto power spectral density (APSD) of detector channel 2.

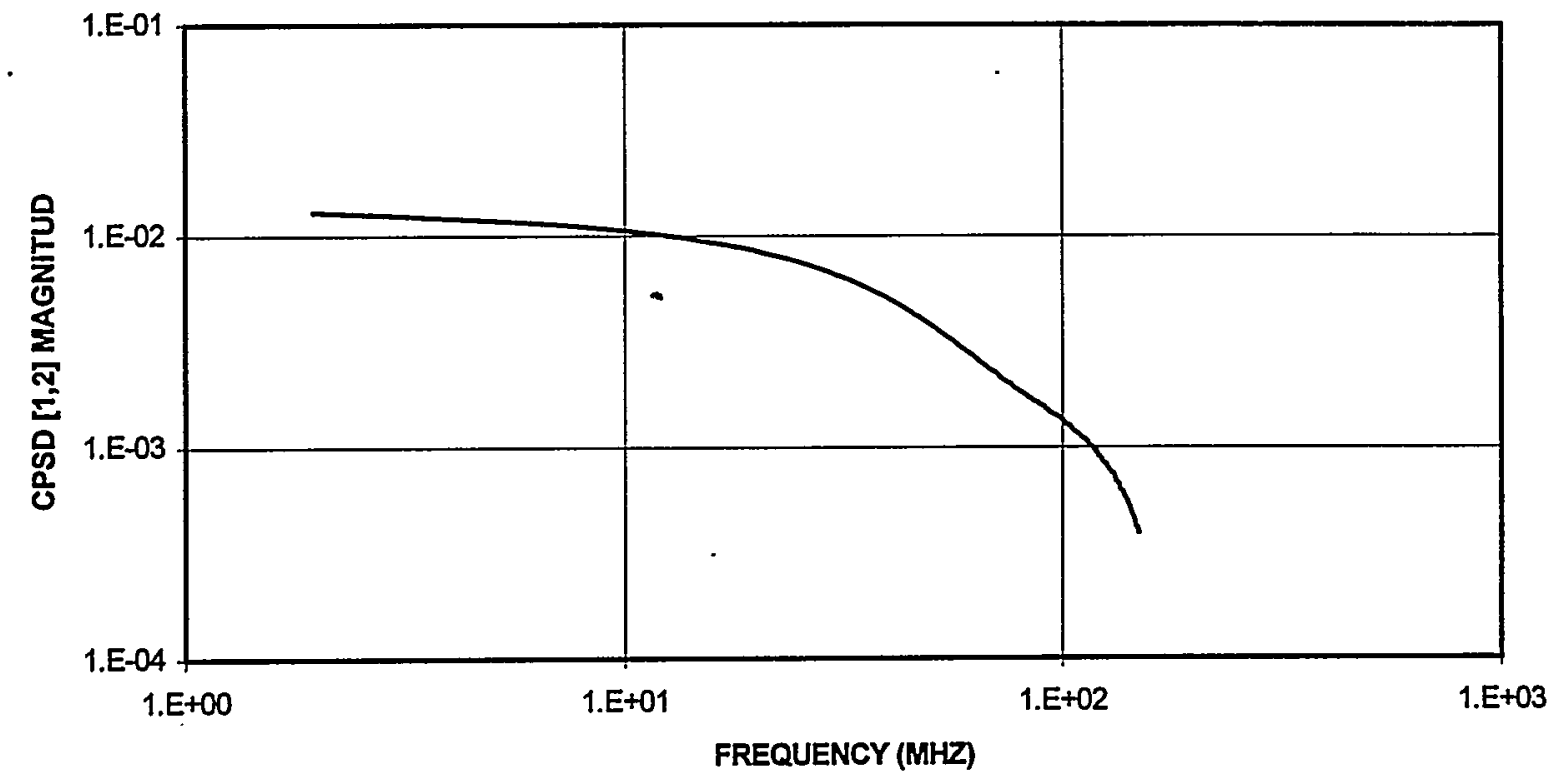

Fig. 2.7. Cross power spectral density between detector channel 2 and the source channel (1) as a function of frequency. 


\subsection{COHERENCES}

The coherence, $\gamma_{i j}^{2}$, is another useful signature. It is the fraction of common information in two channels; it is real; and it varies between 0 and 1 . The coherence is defined as

$$
\gamma_{i j}^{2}=\frac{\left|G_{i j}\right|^{2}}{G_{i i} G_{j j}} .
$$

Measurements are readily performed with NWIS where $\gamma_{i j}^{2}$ is much lower than $10^{-6}$ (Ref. 8). The coherence usually decreases with frequency since there is less correlated signal at high frequency for the CPSDs. Typical coherence values as a function of frequency are given in Fig. 2.8 and 2.9.

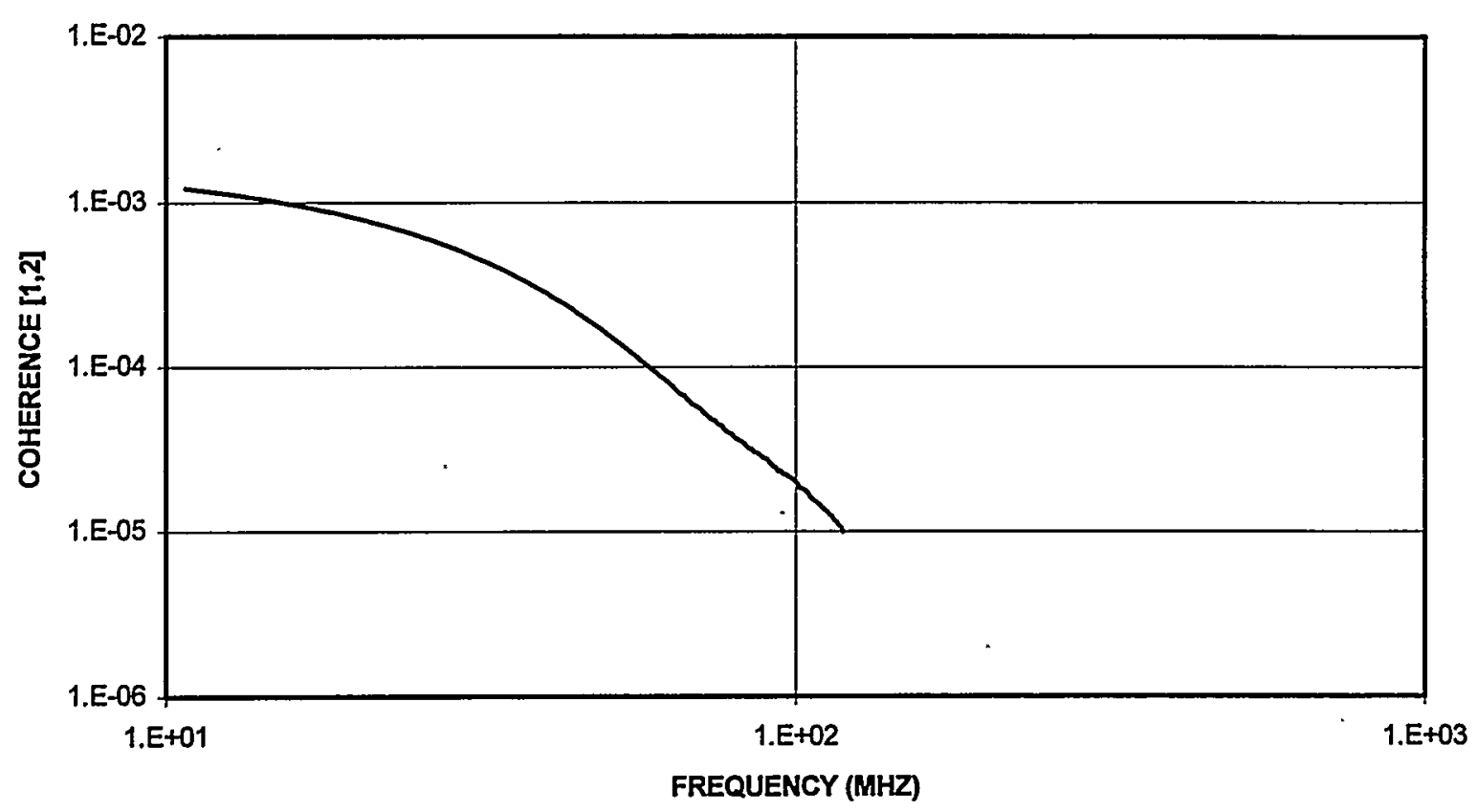

Fig. 2.8. Coherence between a detection channel and the ${ }^{252} \mathrm{Cf}$ source as a function of frequency. 


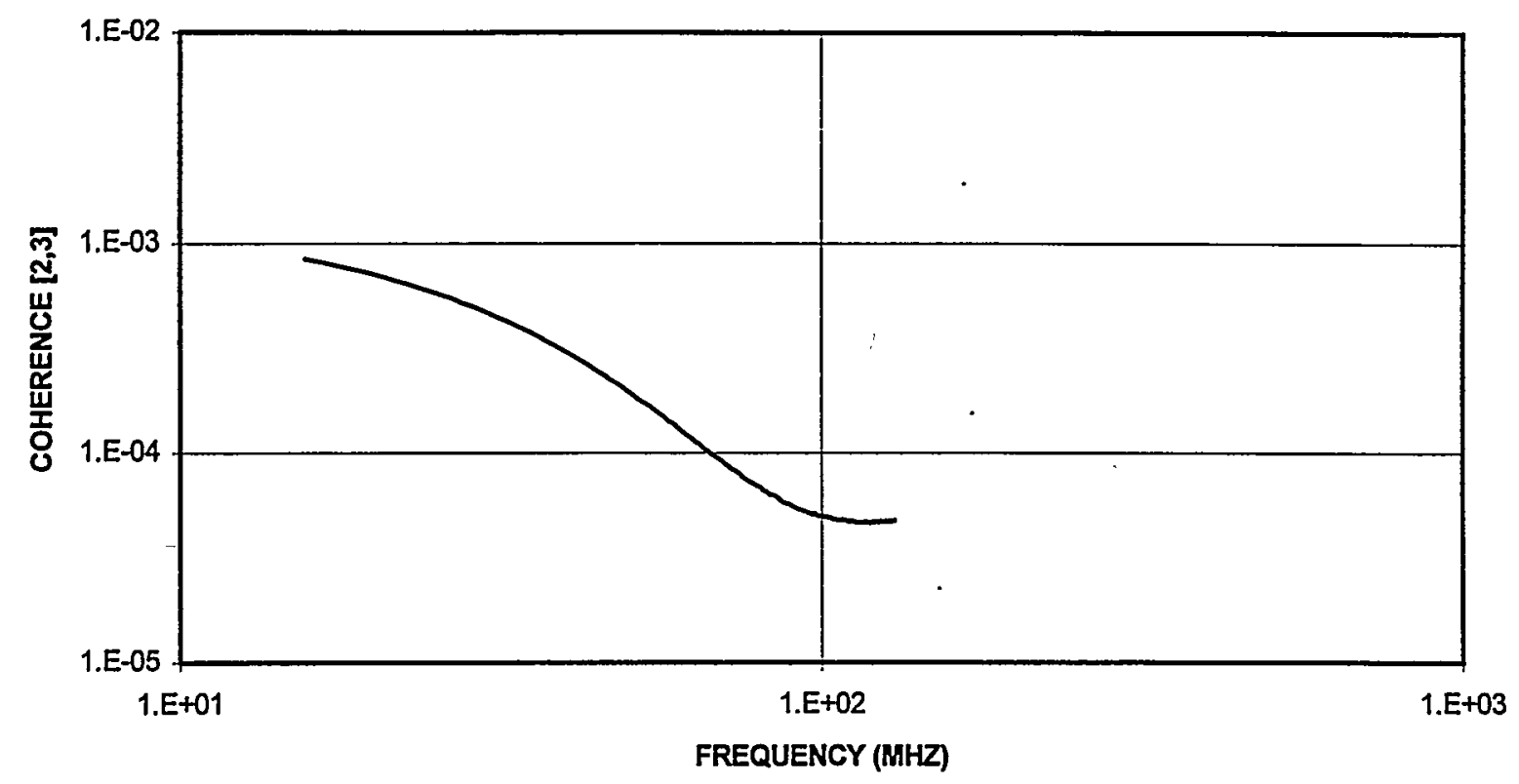

Fig. 2.9. Coherence between two detection channels as a function of frequency.

\subsection{RATIO OF SPECTRAL DENSITIES}

In previous time domain measurements (Ref. 9), it was realized that a measured parameter independent of the detection efficiency could be obtained from measurements if both crosscorrelation functions between detectors and between detectors and the ${ }^{252} \mathrm{Cf}$ source were measured simultaneously. The frequency analysis equivalent of this early time analysis expression is the following ratio of spectral densities.

$$
R_{123}(\omega)=\frac{G_{12}^{*}(\omega) G_{13}(\omega)}{G_{11}(\omega) G_{23}(\omega)}
$$

where ${ }^{*}$ denotes complex conjugation. In this expression detection efficiencies appear in both the numerator and denominator and cancel much in the same way as in beta-gamma coincidence counting methods to obtain the neutron flux in fission reactors. This has lead to a signature which is easily reproduced. Measurements performed 9 years apart with uranium metal cylinders yielded essentially the same value of $R(\omega)$ even though different sources and detectors were used (Ref. 10). In fact, measurement with detectors sensitive only to gamma rays yields the same result as that for detectors sensitive only to neutrons. This ratio is also independent of uncorrelated background which also makes it more useful. A plot of this ratio for an unreflected casting is shown in Fig. 2.10 where the ratio decreases with frequency until it is near 0 at $100 \mathrm{MHz}$. The magnitude of the ratio of spectral densities can be shown theoretically to obey the following relationship, 


$$
|R(\omega)|^{2}=\gamma_{12}^{2} \cdot \gamma_{13}^{2} / \gamma_{23}^{2} .
$$

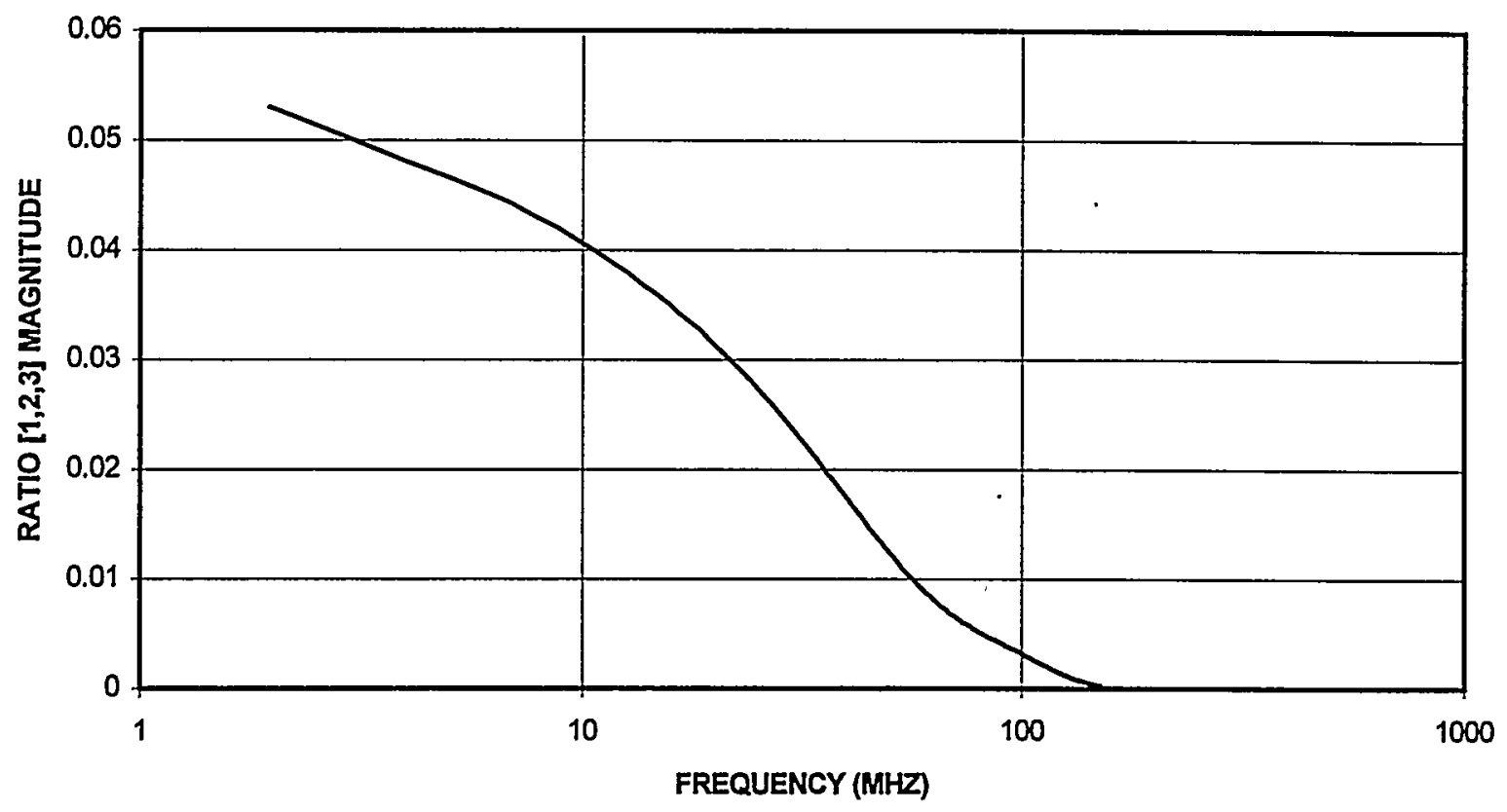

Fig. 2.10. Ratio of spectral densities as a function of frequency.

\subsection{COUNT PROBABILITY DISTRIBUTIONS}

The count probability distributions are obtained from the gate multiplicities, the number of times $\mathrm{m}$ pulses occur in a data block, and are obtained for each channel. The total count probability distributions for all channels is also obtained by treating the sum of all detector channels $(2 \& 3)$ as an additional data stream. These can be either triggered or random. The data given in $t$ his section are random. The count distributions for some of these channels are plotted and compared to that predicted for random counting corrected for the dead times obtained from the autocorrelation functions. The count probability distributions will always be larger than the individual detector distributions. The distribution for the source channel can be used to verify proper operation of the source channel detection system and is shown in Fig. 2.11. The number of blocks of data with a given number of counts in a block are plotted versus the number of counts per block. The spontaneous fission process in the ${ }^{252} \mathrm{Cf}$ is random and thus the measured values for this channel agree with those calculated for random events corrected for the dead time which is obtained from the autocorrelation function of this channel (Fig. 2.2). The count distribution for detector channel 2 is plotted in Fig. 2.12 and the measured values are only slightly larger than random counting, but significant. A typical plot for the combined detector count distribution is shown in Fig. 2.13. The count distribution 


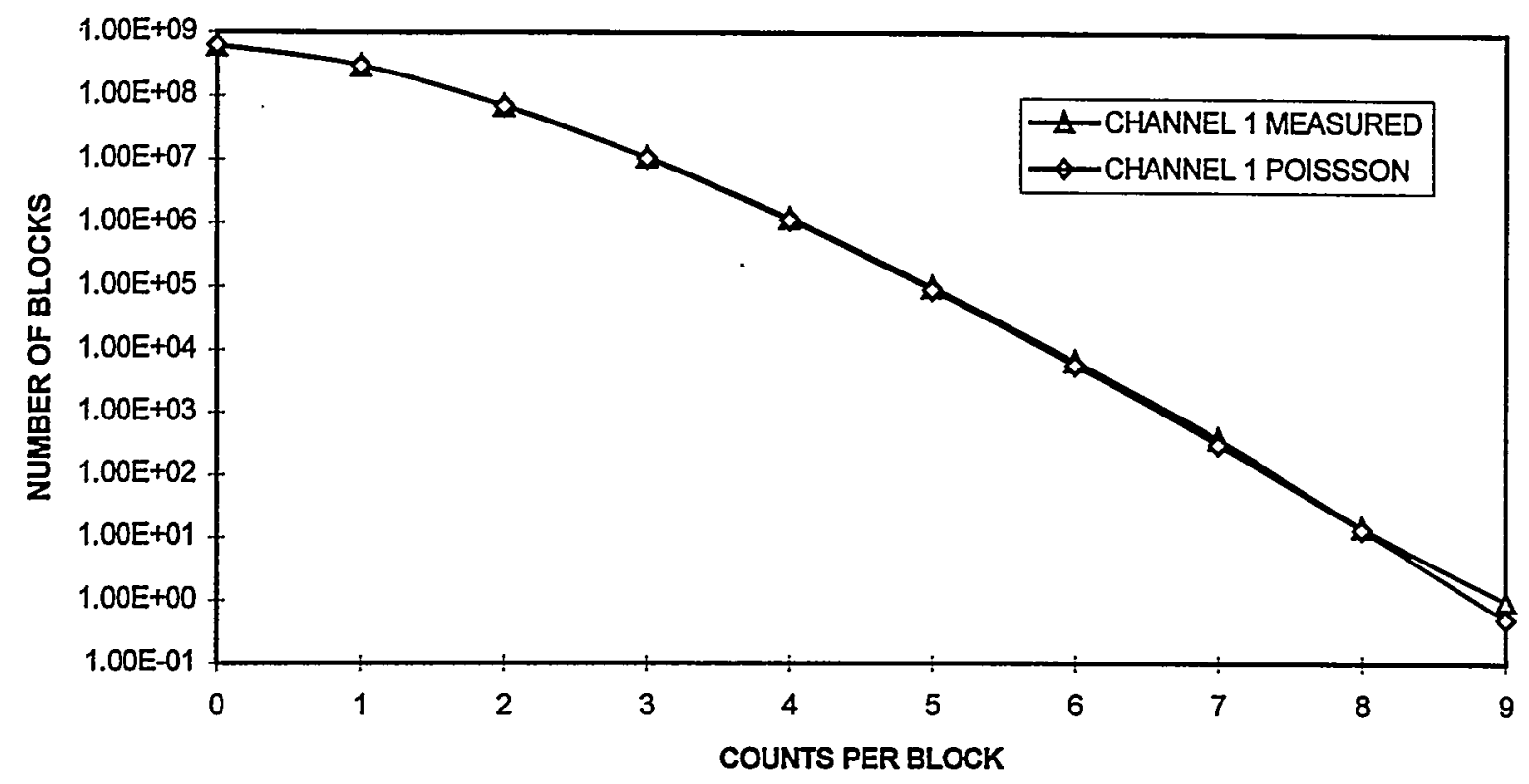

Fig. 2.11. Gate multiplicities for the source ionization chamber channel.

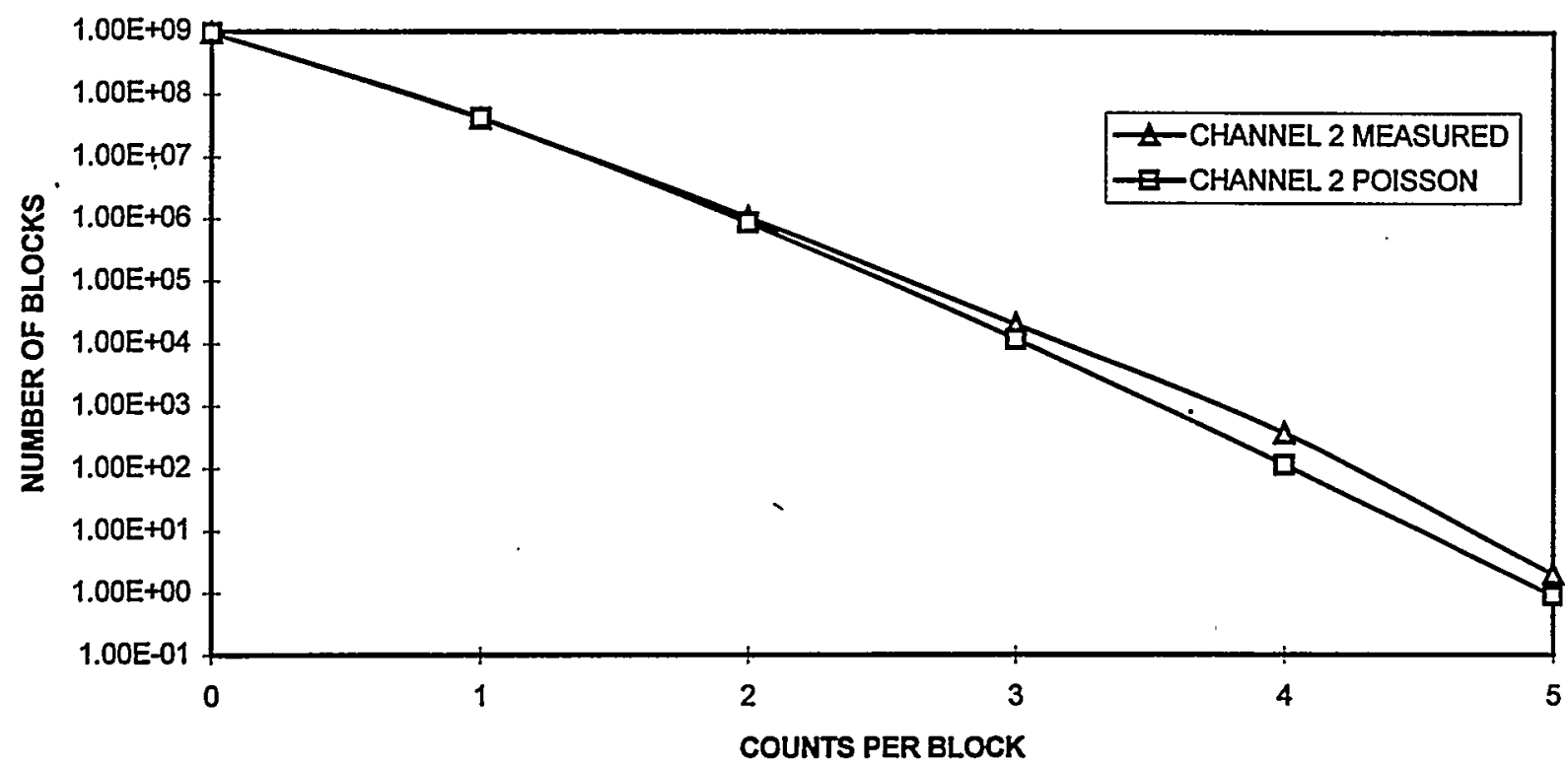

Fig. 2.12. Gate multiplicities for a single detector channel (2). 


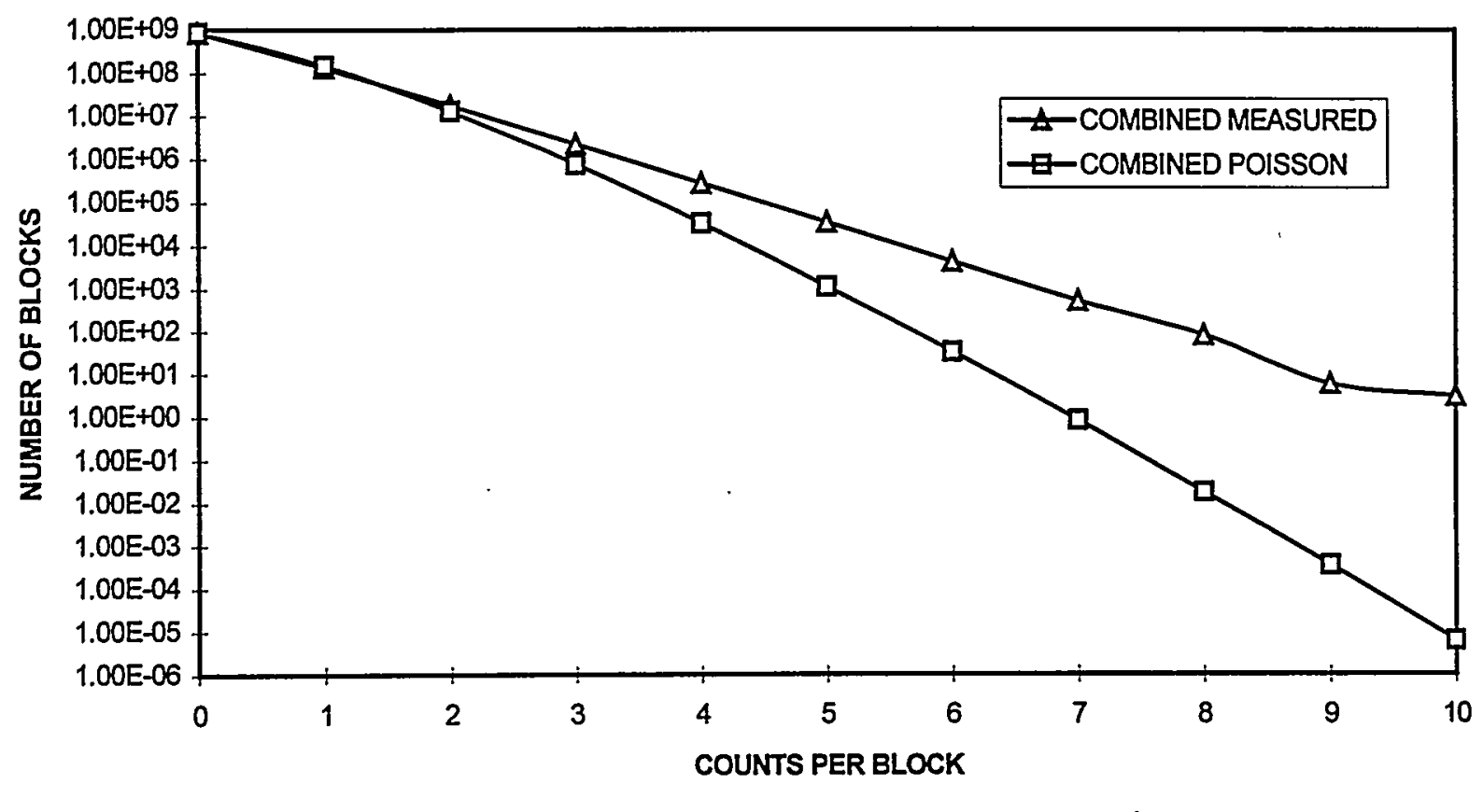

Fig. 2.13. Combined gate multiplicity for all detector channels.

obtained from the sum of detectors (Fig. 2.13) is considerably larger than that for a single detector and has count events as high as 10. For comparison purposes, the values should be expressed in terms of probabilities so that comparisons made do not depend on the number of blocks in a measurement. From these, the Feynman variance can be obtained as $\left(\overline{c^{2}}-\bar{c}^{2}\right) / \bar{c}$ where $\mathrm{c}$ is the number of counts per data block; also the measurements or reduced moments.

The ratios of probabilities, triples/singles, quadruples/singles, quintuples/singles are plotted as a function of the doubles/singles ratio in Fig. 2.14. To show the usefulness of this type of plot, data have been included for the casting with no moderator around it 2.5 in. and $5.1 \mathrm{in}$. thick. Since there is less fission without moderator, the ratios are generally smaller than those with a moderator. For higher order ratios (greater than 6/1) the statistical uncertainty is large. The ratios for the casting with $7.62 \mathrm{~cm}$ polyethylene reflector are given in Table 2.1. 
Table 2.1 Ratios of combined count probability distributions for all detectors for an HEU-metal casting with 3-in. of moderator

\begin{tabular}{|c|c|}
\hline Ratio to singles & Value \\
\hline \hline $2 / 1$ & $1.92 \mathrm{E}-01$ \\
\hline $3 / 1$ & $2.74 \mathrm{E}-02$ \\
\hline $4 / 1$ & $3.87 \mathrm{E}-03$ \\
\hline $5 / 1$ & $5.49 \mathrm{E}-04$ \\
\hline $6 / 1$ & $8.03 \mathrm{E}-05$ \\
\hline $7 / 1$ & $1.24 \mathrm{E}-05$ \\
\hline $8 / 1$ & $1.95 \mathrm{E}-06$ \\
\hline $9 / 1$ & $2.73 \mathrm{E}-07$ \\
\hline $10 / 1$ & $2.27 \mathrm{E}-08$ \\
\hline
\end{tabular}

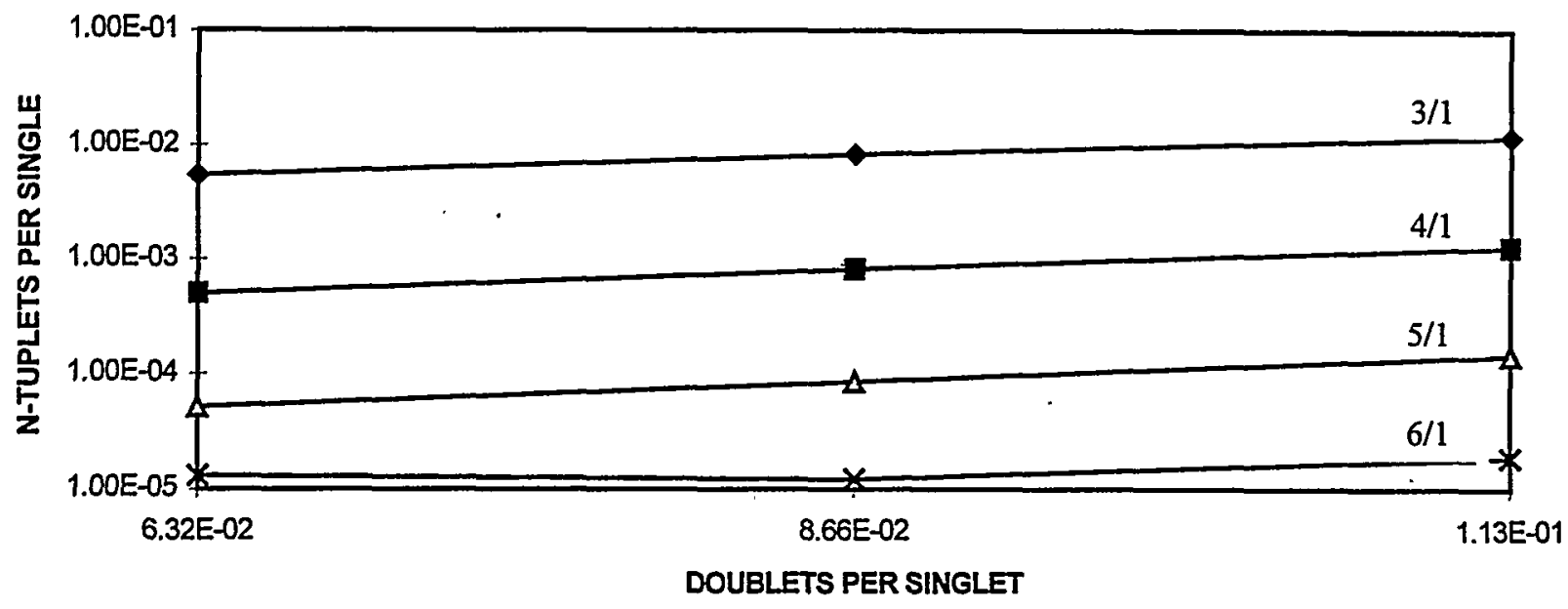

Fig. 2.14. Ratios of n-tuplets to singles as a function of doublets to singlets for a uranium casting with varying moderator thickness. $(0,2.5$, and $5.1 \mathrm{~cm}$ thick; with no moderator the doublets to singlets ratio is $6.32 \times 10^{-2}$.) 


\section{NWIS PROCESSOR AND ELECTRONICS}

This section provides a brief discussion of the electronics components of the Nuclear Weapons Identification System (NWIS). This description begins with an overview of the configuration of NWIS and then provides a brief description of each component. A brief description of the electronics components, the data acquisition process, and the data processing is discussed in the following sections.

\subsection{SYSTEM OVERVIEW}

As previously stated the measurements requires the use of a ${ }^{252} \mathrm{Cf}$ source contained in an ionization chamber, radiation detectors, detector electronics, data processing boards, and a computer for data acquisition and display. A photograph of a typical NWIS ${ }^{11}$ configuration is shown in Fig. 3.1 deployed around a container with weapons component. The source is located on one side of the container and the detectors are located on the other side of the container. The source and detector signals are sent to electronic modules for processing and then the signals are sent to the data processing components for data acquisition. A block diagram of the configuration is shown in Fig. 3.2.

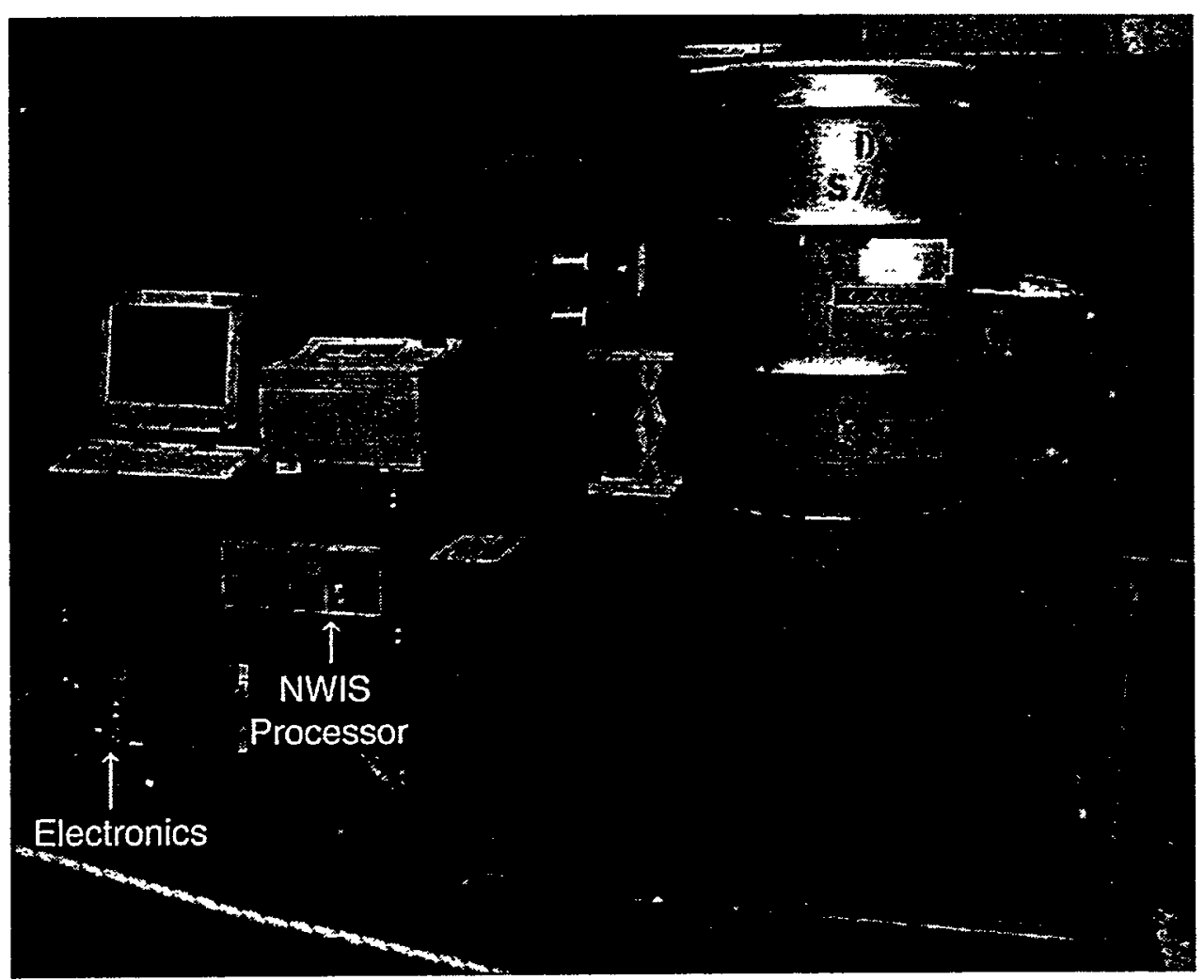

Fig. 3.1. NWIS signature acquisition with cart-portable system at the Y-12 plant (1996). 


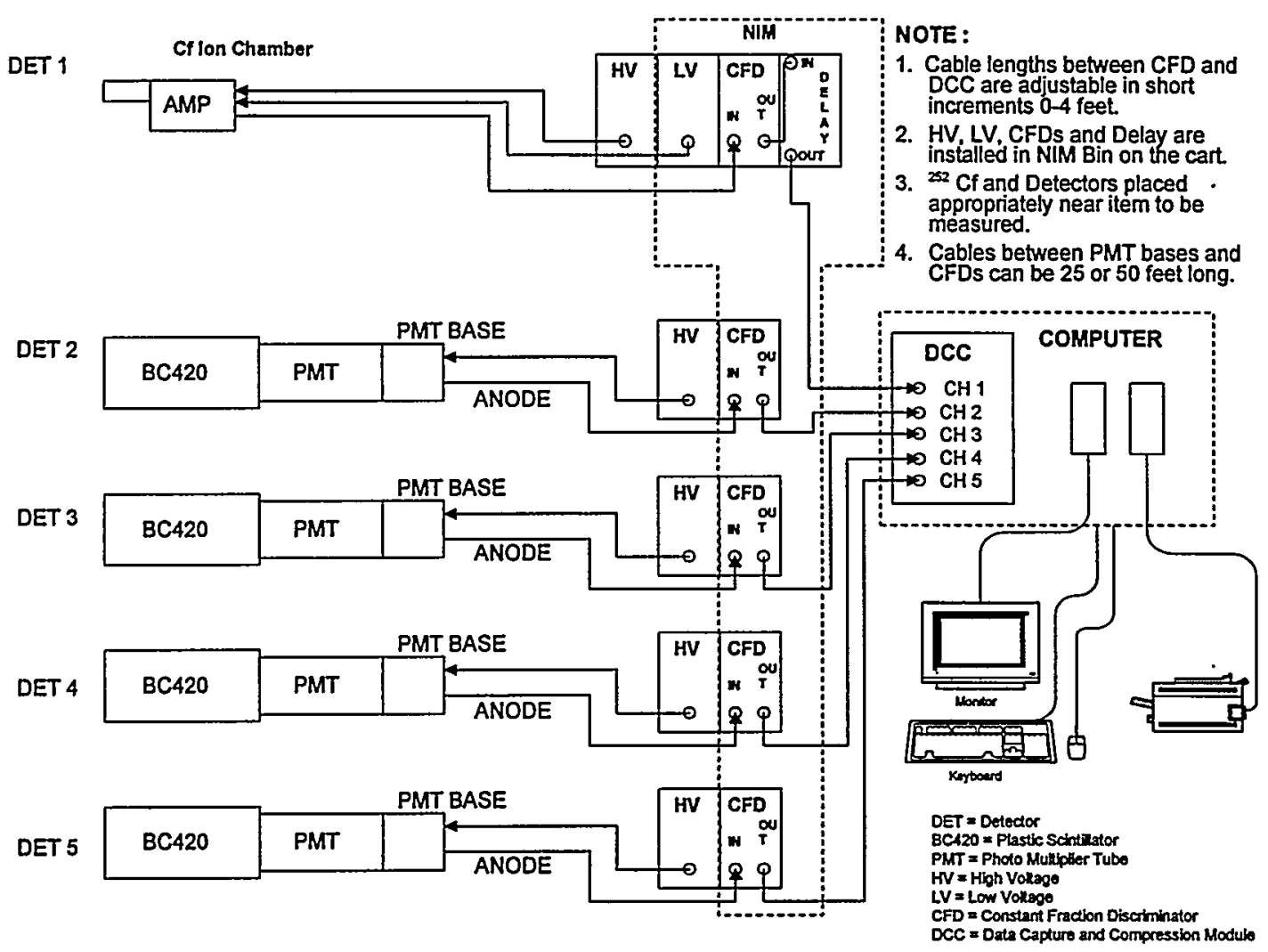

Fig. 3.2. Block diagram of nuclear detection electronic components.

\section{$3.2{ }^{252}$ CF SOURCE ELECTRONICS}

A photograph of the source ionization chamber and its amplifier is shown in Fig. 3.3. The ${ }^{252} \mathrm{Cf}$-source ionization chamber produces an electrical pulse each time the source emits neutrons and gamma rays. ${ }^{12}$ An amplifier is used to increase the amplitude (size) of the pulse from the source ionization chamber. The amplifier is referred to as a high-gain fast amplifier. The high-gain fast amplifier requires a high voltage (HV) and a low voltage (LV) supply as inputs to the amplifier and produces an electrical pulse as output. The commercially available power supply is a HV power supply and is used to supply power to the source high-gain fast amplifier. The HV is passed through the amplifier to the plates of the ionization chamber. The output of the source high-gain fast amplifier is input to a commercially available constant fraction discriminator (CFD). The CFD eliminates unwanted pulses and produces an output pulse that has constant amplitude and adjustable width. The output of the constant fraction discriminator is input to a delay module, which is used to control the arrival time of pulses from the source to the data processor. The present configuration of these electronic components is shown schematically in Fig. 3.2. The CFD and the delay module are contained within a commercially available nuclear instrument module (NIM) bin that supplies power to these components. An assortment of commercially available cables and connectors are used to connect the source to the electronic components and the data acquisition components. 


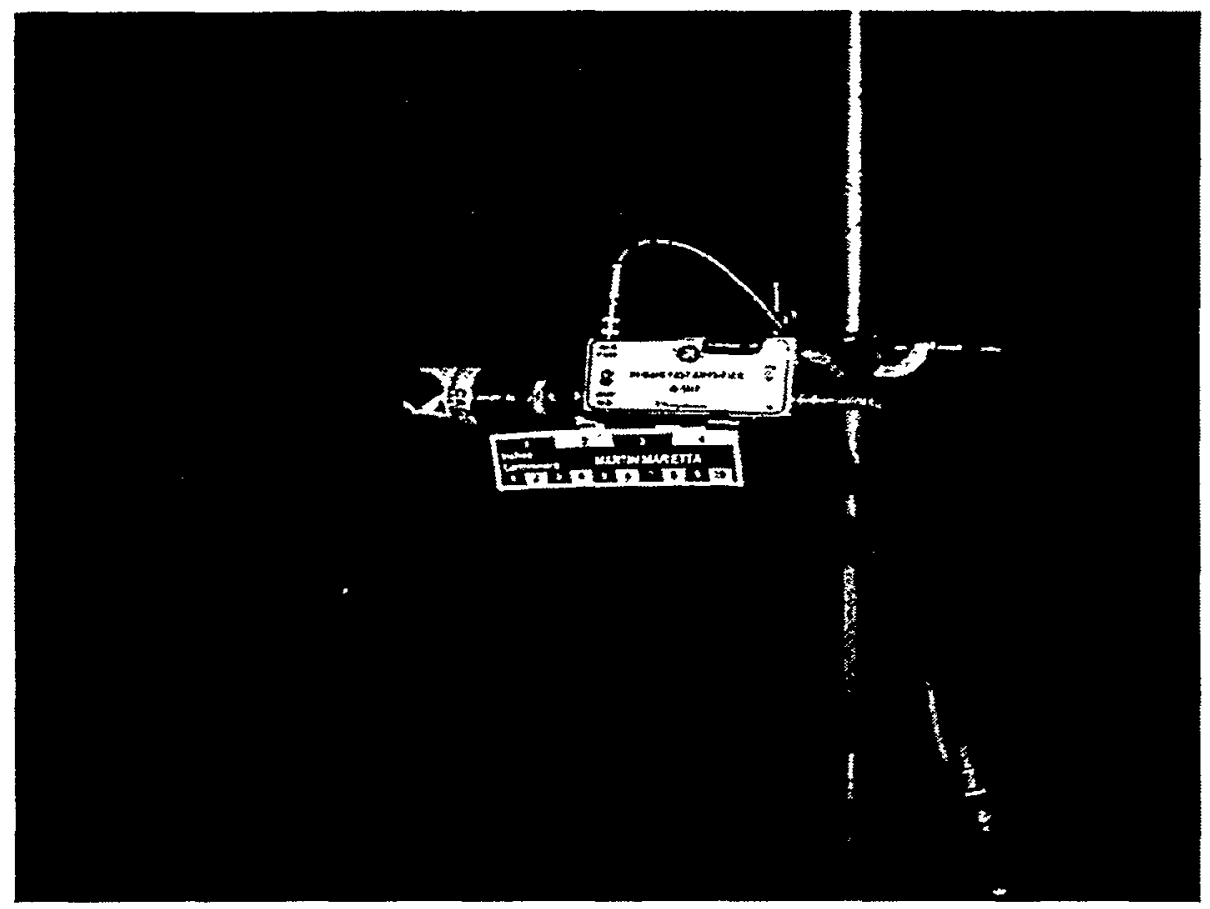

Fig. 3.3. ${ }^{252} \mathrm{Cf}$ source ionization chamber and amplifier.

\subsection{DETECTION SYSTEM}

The detectors are commercially available organic plastic scintillators that are used to measure fast neutrons and gamma rays. A photograph of the detectors is shown in Fig. 3.4. The detectors for these experiments are numbered as follows: detectors 2 and 3 are the bottom of the $2 \times 2$ array of detectors with detector 3 visible in the photograph with detector 2 behind it in the photograph. Similarly, detector 5 is on top of 3 and is visible in the photograph. Detector 4 is behind it with only its top surface visible. Neutrons and gamma rays interact within the detector and produce light. The light is converted to an electrical pulse using a commercially available photo-multiplier tube (PMT) and a PMT base that provides power to the PMT. A commercially available high voltage power supply is used to power the PMT base. The output of the PMT base is sent to a constant fraction discriminator (CFD), which eliminates unwanted pulses and produces an output pulse that has constant amplitude and adjustable width. The constant fraction discriminator has four independent inputs and outputs. The output of the CFD is sent to the data processor. The configuration of these electronic components is shown schematically in the block diagram of Fig. 3.2. The constant fraction discriminator is located within a nuclear instrument module (NIM) bin that supplies power to the components. An assortment of cables and connectors are used to connect the detectors to the processing electronics and to the data acquisition components. 


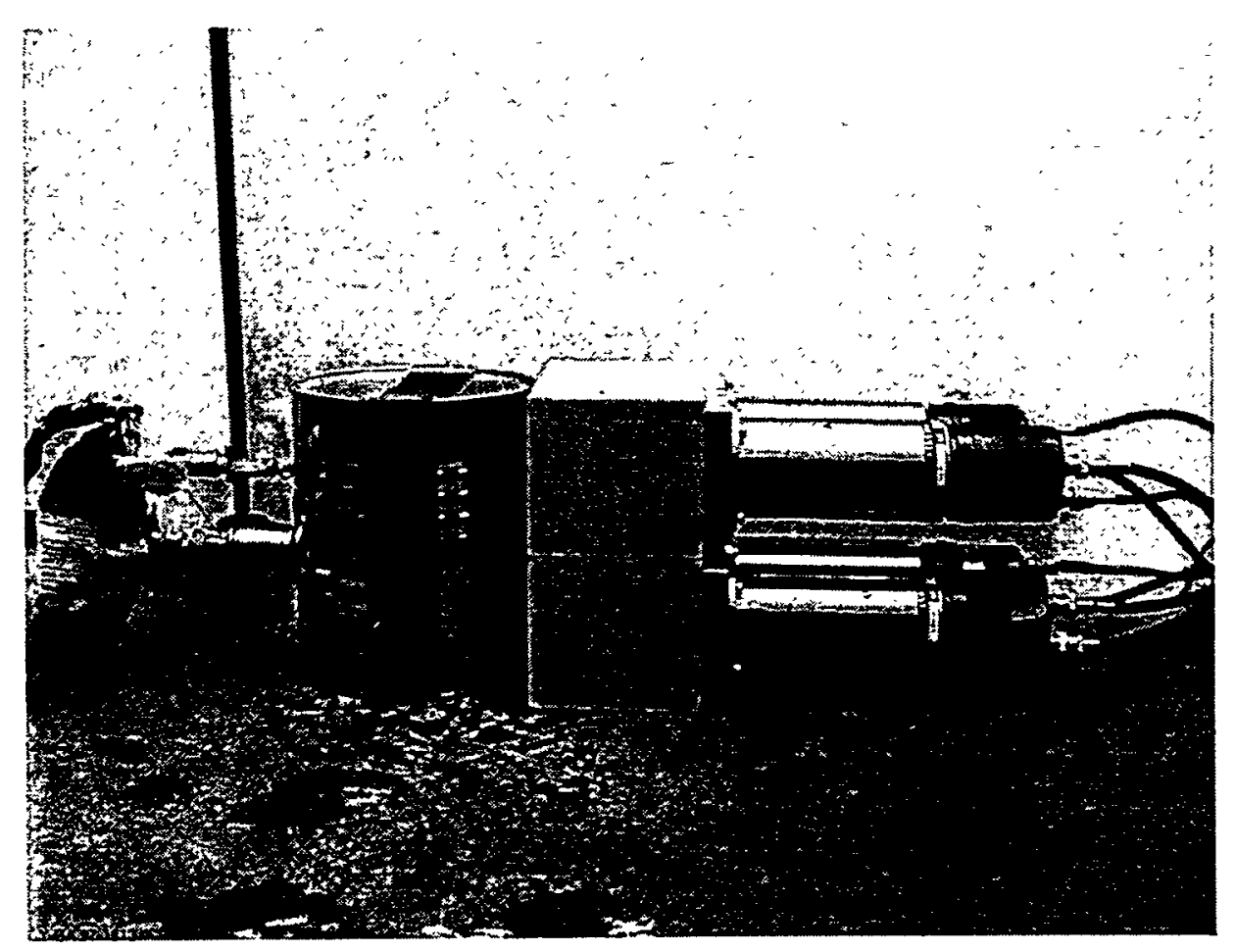

Fig. 3.4. Typical source-detector configuration for measurements with unmoderated high enriched uranium metal castings in containers.

\subsection{DATA ACQUISITION COMPONENTS}

The data acquisition components are comprised of two electronic boards that are installed in a commercially available computer. The data capture and compression (DCC) module is located on one of the electronics boards and is used to acquire the signals from the constant fraction discriminators. A photograph of this module is shown in Fig. 3.5. The output of the DCC module is sent to a data processing component that sends the data to the computer. The DCC module requires the use of a separate power supply. The DCC module and the data processing module are referred to as a board set. These boards are designed by ORNL and commercially fabricated with commercially available electronic components except for the processor chip which is especially designed and fabricated by a commercial chip maker. 


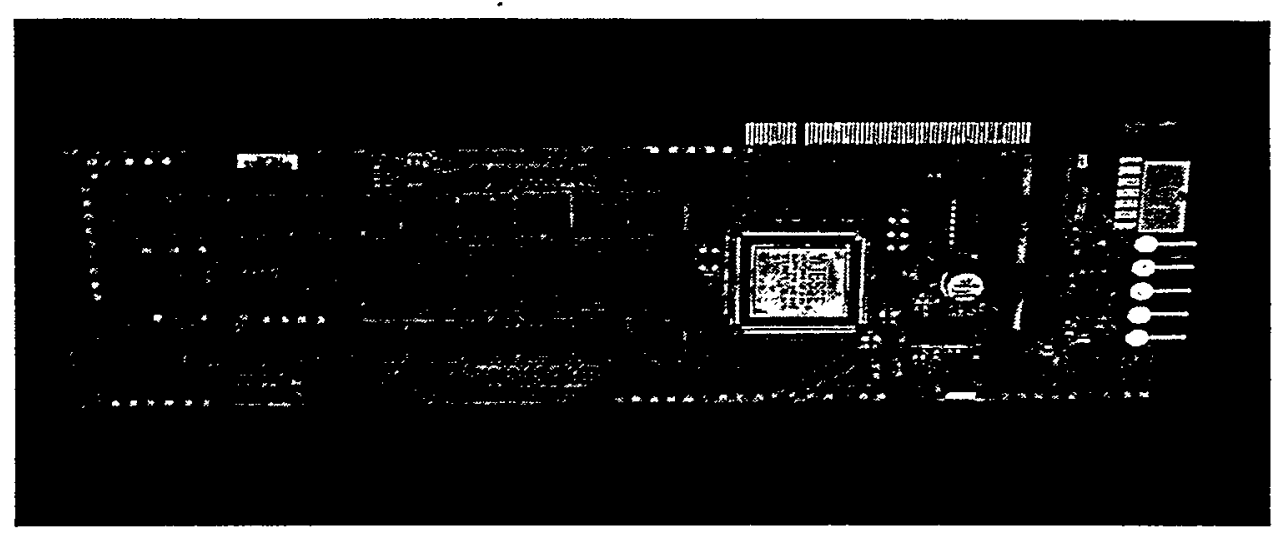

Fig. 3.5. DCC electronic board.

\section{DESCRIPTION OF URANIUM METAL CASTINGS}

All of the annular castings were geometrically the same and had an $8.89-\mathrm{cm} \mathrm{ID,} \mathrm{a} 12.7-\mathrm{cm}$ OD and a length of $\sim 15.24 \mathrm{~cm}$. A photograph of a casting is provided in Fig. 4.1 in a steel tray. All castings were contained in stainless steel cans that had 15.6-cm OD and were 22.4 $\mathrm{cm}$ tall with a $0.15-\mathrm{cm}$ wall thickness as shown in Fig. 4.2. The enrichment, net mass, uranium mass. fraction, and uranium mass for each casting is provided in Table 4.1. The density of the $93.15 \mathrm{wt} \%{ }^{235} \mathrm{U}$ enriched casting is $18.76 \mathrm{~g} / \mathrm{cm}^{3}$, and the density of the other castings will be slightly more due to the increased amount of ${ }^{238} \mathrm{U}$ in the casting. These castings are comprised almost entirely of uranium but do have a small amount of impurities such as oxygen, carbon, nitrogen, etc. Each of these castings contains about the same amount of impurities. Enrichment was essentially the only parameter that was changed from one casting to another.

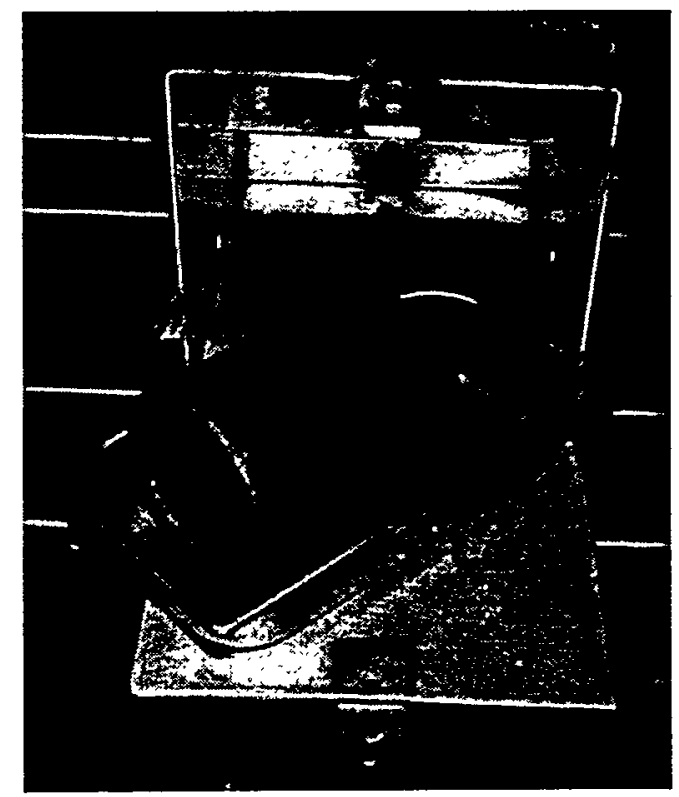

Fig. 4.1. High enriched uranium metal annular casting. 


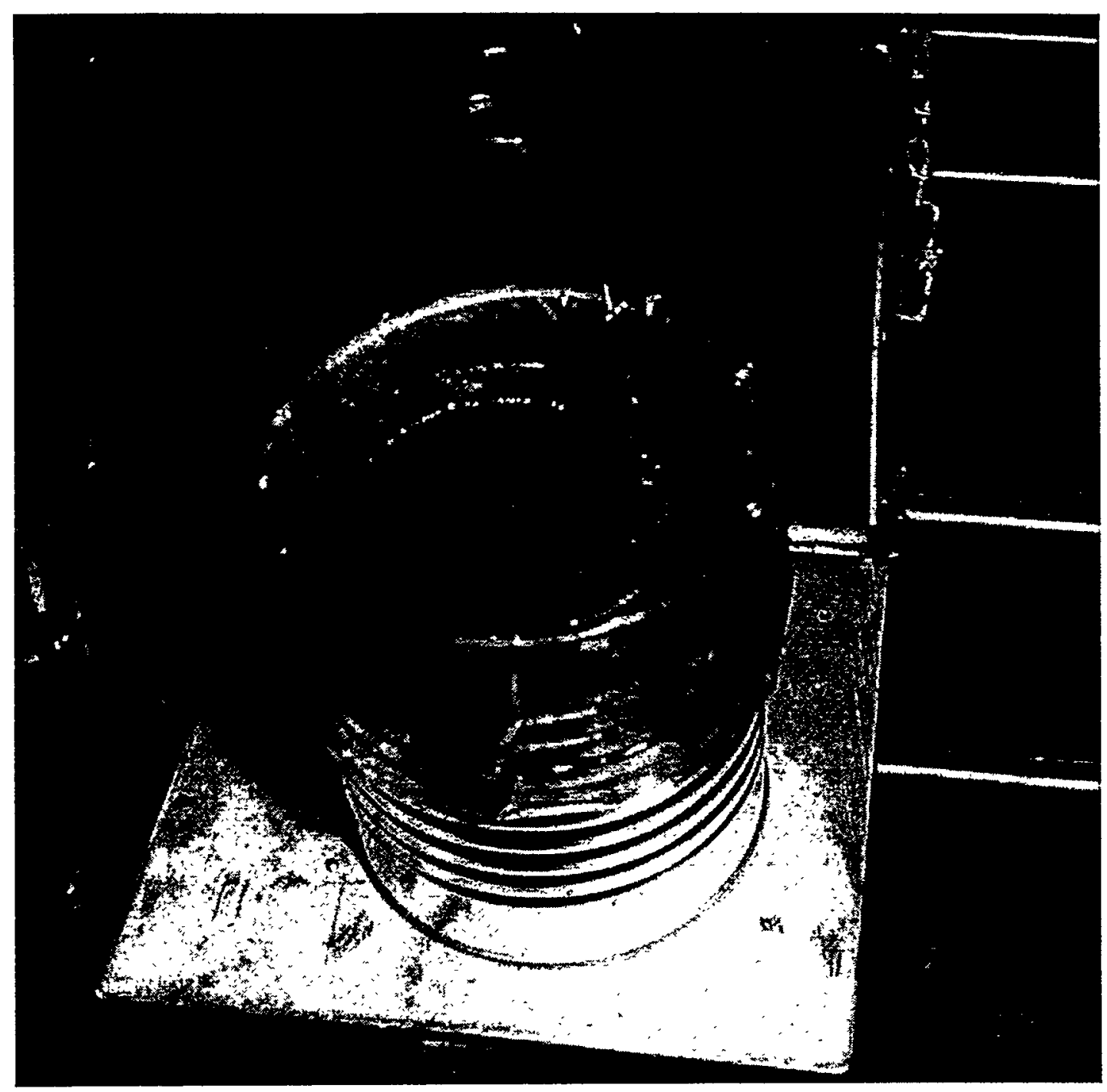

Fig. 4.2. Uranium metal casting in steel container.

Table 4.1. Annular uranium metal castings

\begin{tabular}{|c|c|c|c|}
\hline $\begin{array}{c}\text { Enrichment } \\
\left(\mathrm{wt} \%{ }^{23} \mathrm{U}\right)\end{array}$ & $\begin{array}{c}\text { Net mass } \\
(\mathrm{kg})\end{array}$ & $\mathrm{kg} \mathrm{U} / \mathrm{kg}$ metal & $\begin{array}{c}\text { Uranium mass } \\
(\mathrm{kg})\end{array}$ \\
\hline 93.15 & 17.646 & 0.99932 & 17.634 \\
\hline 90.03 & 17.672 & 0.99932 & 17.660 \\
\hline 84.97 & 17.47 & 0.99914 & 17.455 \\
\hline 80.09 & 17.457 & 0.99926 & 17.444 \\
\hline
\end{tabular}




\section{DESCRIPTION OF MEASUREMENTS WITH CASTINGS OF VARYING ENRICHMENT}

The NWIS measurements were performed with standard annular uranium metal castings of four different enrichments $\left(80.09 \mathrm{wt} \%{ }^{235} \mathrm{U}, 84.97 \mathrm{wt} \%{ }^{235} \mathrm{U}, 90.03 \mathrm{wt} \%{ }^{235} \mathrm{U}\right.$, and $93.15 \mathrm{wt} \%$ ${ }^{235} \mathrm{U}$ ). The annular castings were placed inside a $7.62-\mathrm{cm}$ thick polyethylene reflector with the source on one side of the casting and four detectors located on the opposite side as shown in Fig. 5.1. A solid 7.62-cm thick polyethylene reflector was placed on the top and the bottom of the U-shaped polyethylene reflector shown in Fig. 5.2.

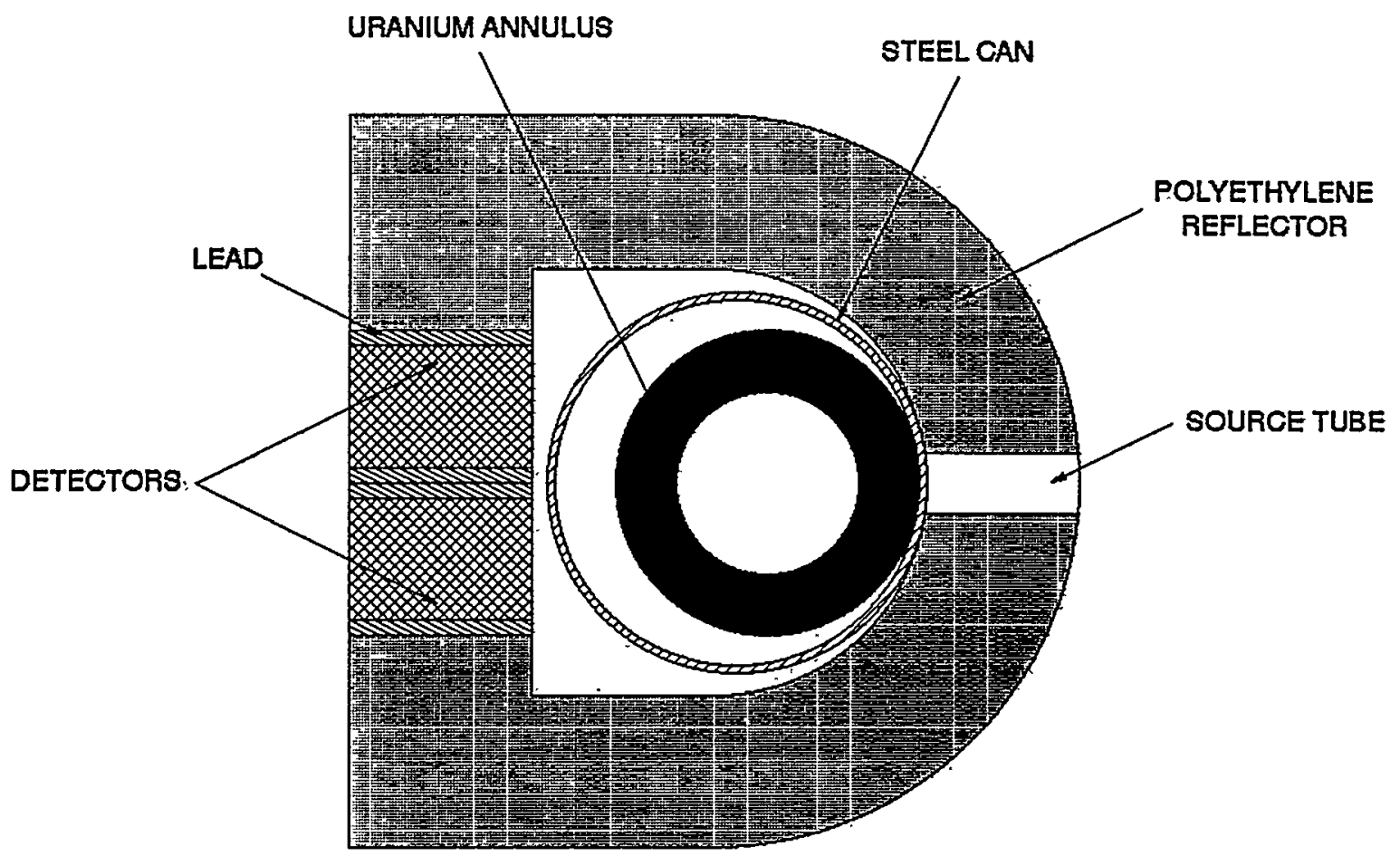

Fig. 5.1. Sketch of top view of measurement configuration with annular casting.

The source was located $7.62 \mathrm{~cm}$ from the bottom of the casting and was in contact with the casting container. The ${ }^{252} \mathrm{Cf}$ source had a mass of $\sim 0.7 \mu \mathrm{g}$ and more than $99 \%$ of the source spontaneous fission events were counted. The four detectors used in these measurements were fast plastic scintillators that are sensitive to both gamma rays and neutrons and were positioned in a $2 \times 2$ array. Detectors \#4 and \#5 were positioned above detectors $\# 2$ and \#3 respectively. These detectors are $7.62-\mathrm{cm}$ wide and tall and $10.16-\mathrm{cm}$ thick and had a $0.635-$ $\mathrm{cm}$ thick lead shield on the sides with no shielding on the front face of the detectors. The thresholds for these detectors were set such that neutrons above $1.5 \mathrm{MeV}$ would be detected. Additional measurements were performed with the casting removed from the moderator to obtain a reference measurement for the neutron time of flight. 


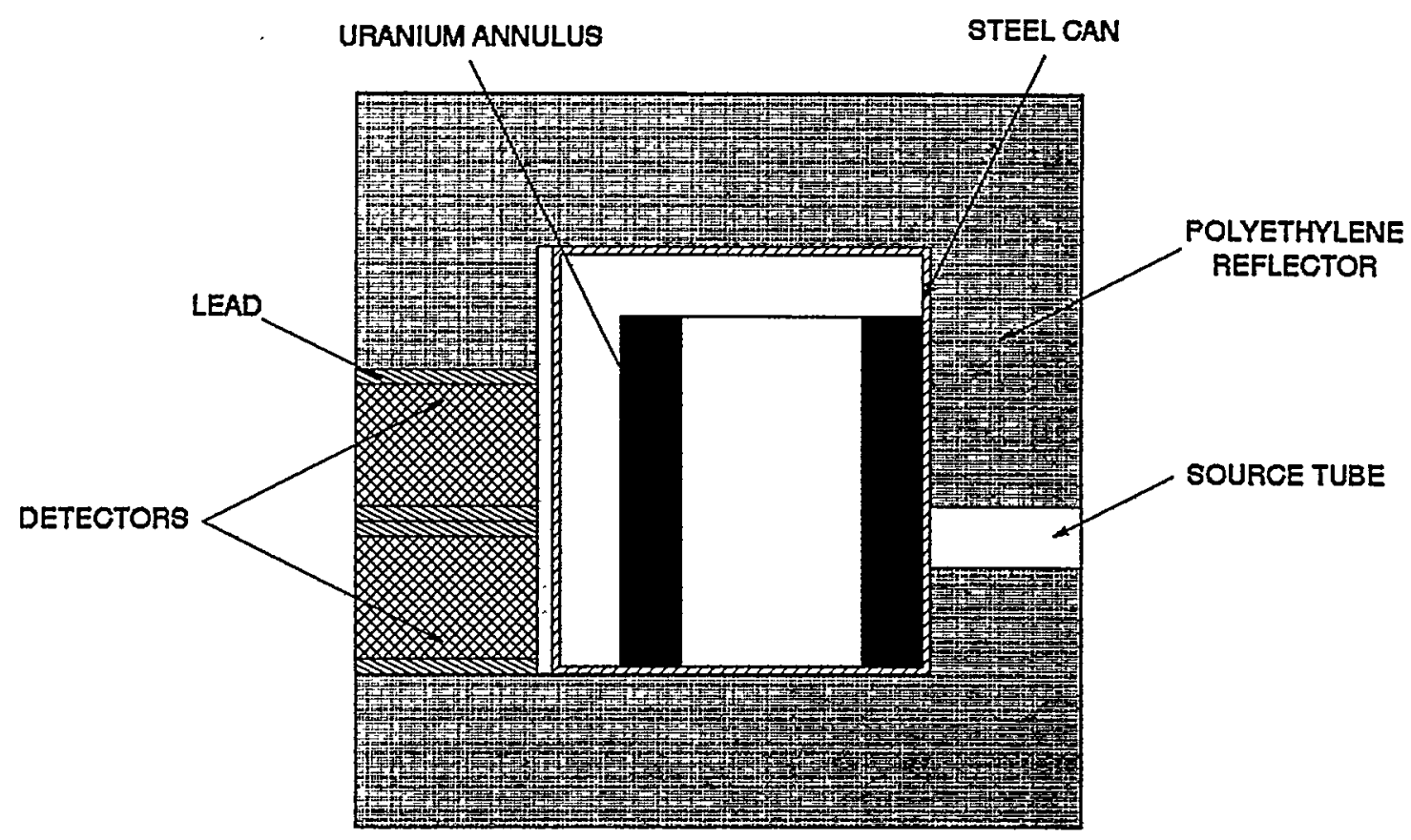

Fig. 5.2. Sketch of side view of measurement configuration with annular casting. 


\section{RESULTS OF MEASUREMENTS WITH CASTINGS \\ OF VARYING ENRICHMENT}

As previously described, the time-dependent detector responses obtained from the measurements are used to generate a variety of correlation functions that are Fourier transformed to obtain their respective frequency spectra. This sections presents many of the parameters obtained from these measurements in both the time and frequency domain, shows the functional dependence of many of the measured time or frequency functions, and shows plots of some of the parameters with ${ }^{235} \mathrm{U}$ mass or enrichment. These measurements with varying enrichments were as described in Fig. 6.1 and 6.2 with $7.62 \mathrm{~cm}$.-thick polyethylene.

\subsection{TIME-DEPENDENT SIGNATURES}

In the measurements, both auto and cross-correlation functions are generated from the measured time responses. The cross-correlation functions are typically normalized to the source count rate to remove their dependence on the source. The background subtracted correlation functions are actually covariance functions because the accidental correlations have been removed. Covariance functions are generated from the correlation functions by removing accidental correlation rates of the detectors, that is subtracting the product of the detector count rates per time interval for two detection signals that are correlated. The covariance functions are independent of counts due to background radiation although their uncertainties are noted. The detector autocorrelation functions should be sensitive to fissile mass. As an example one of the detector autocorrelation functions is shown in Fig. 6.1. This correlation function exhibits an exponential decrease in the region 40 to $80 \mathrm{~ns}$, but does not exhibit an exponential decay prior to $20 \mathrm{~ns}$ due to the dead time of the detection system as shown in Fig. 6.1. As can be seen from this figure, the time-dependent autocorrelation function has a slight dependence on fissile mass. The detector autocorrelation functions were integrated over time to obtain the total correlated counts for the detectors and are presented in Table 6.1 along with the sensitivity coefficient for the integrals. The integral of the total correlated counts increases as fissile mass increases. The integral of the autocorrelation functions increases approximately $13 \%$ from 13.97 to $16.43 \mathrm{~kg}$ of ${ }^{235} \mathrm{U}$.

A plot of the integral of one of the detector autocorrelation functions is given in Fig. 6.2 and is a linear function of ${ }^{235} \mathrm{U}$ mass. The sensitivity of the integral of the autocorrelation function to fissile mass was determined by dividing the slope of a linear fit to the data by the average value of the integral of the autocorrelation function. This sensitivity coefficient is the derivative of the logarithm of the linear fit. The sensitivity coefficients for the integral of the detector autocorrelation functions are approximately 0.06 per $\mathrm{kg}^{235} \mathrm{U}$.

A comparison of a source-detector cross-correlation function for the different mass castings is shown in Fig. 6.3. The source-detector cross-correlation function is sensitive to fissile mass as evident in Fig. 6.3. The directly transmitted gamma rays are not very sensitive to the fissile mass because gamma ray attenuation is predominately due to atomic rather than nuclear 


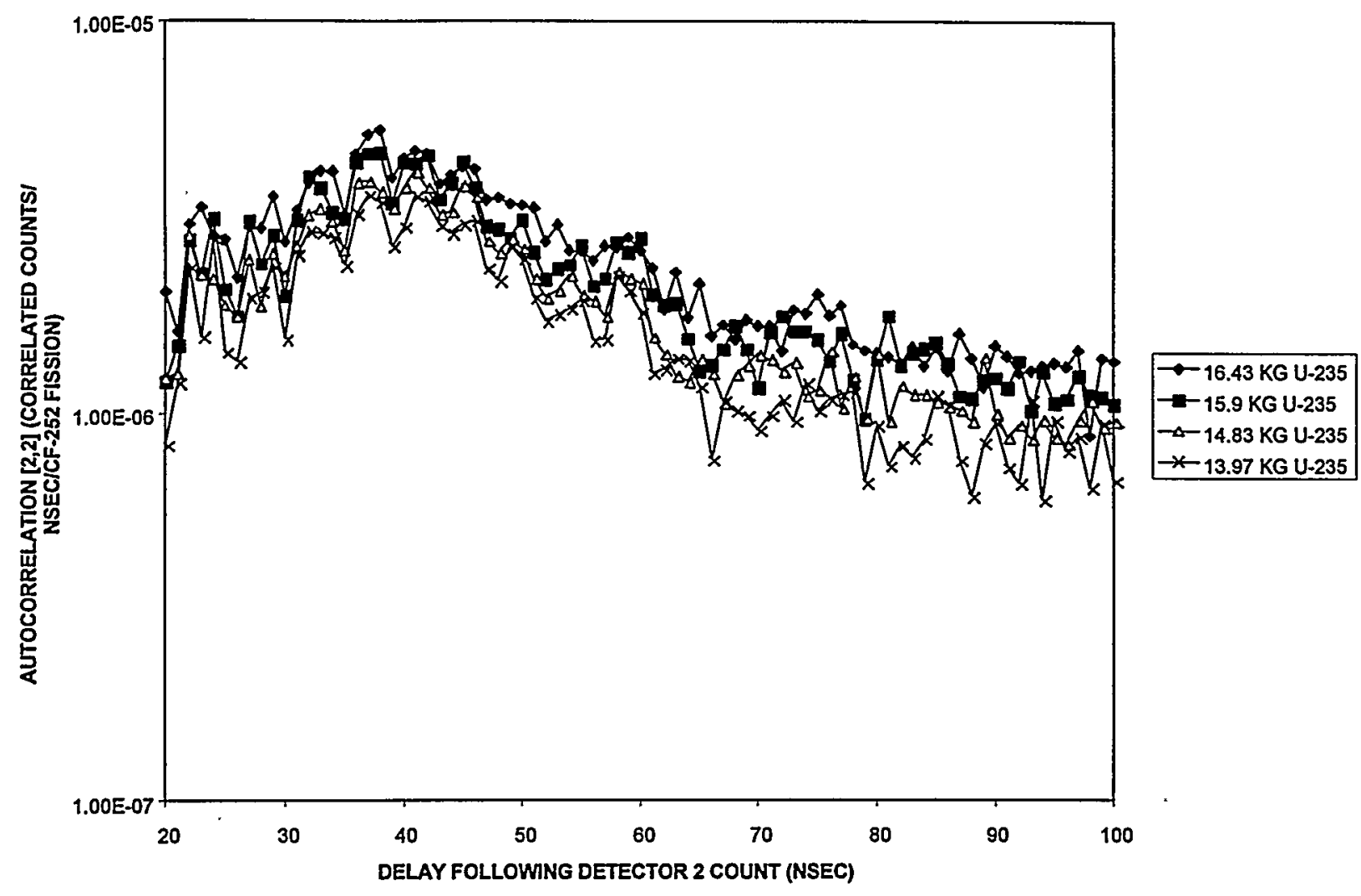

Fig. 6.1. Detector autocorrelation function $[2,2]$ for uranium metal castings.

Table 6.1. Integral of detector autocorrelation functions and sensitivity coefficients for annular uranium metal castings

\begin{tabular}{|c|c|c|c|c|}
\hline${ }^{235} \mathrm{U}$ mass $(\mathrm{kg})$ & $\mathrm{R}_{22}$ & $\mathrm{R}_{33}$ & $\mathrm{R}_{44}$ & $\mathrm{R}_{55}$ \\
\hline 13.97 & $8.25 \mathrm{E}-02$ & $8.36 \mathrm{E}-02$ & $7.68 \mathrm{E}-02$ & $7.64 \mathrm{E}-02$ \\
\hline 14.83 & $8.70 \mathrm{E}-02$ & $8.43 \mathrm{E}-02$ & $8.09 \mathrm{E}-02$ & $7.67 \mathrm{E}-02$ \\
\hline 15.90 & $9.17 \mathrm{E}-02$ & $9.41 \mathrm{E}-02$ & $8.47 \mathrm{E}-02$ & $8.52 \mathrm{E}-02$ \\
\hline 16.43 & $9.59 \mathrm{E}-02$ & $9.72 \mathrm{E}-02$ & $8.83 \mathrm{E}-02$ & $8.78 \mathrm{E}-02$ \\
\hline $\begin{array}{l}\text { Sensitivity } \\
\text { Coefficient }\end{array}$ & 0.0580 & 0.0665 & 0.0538 & 0.0613 \\
\hline
\end{tabular}

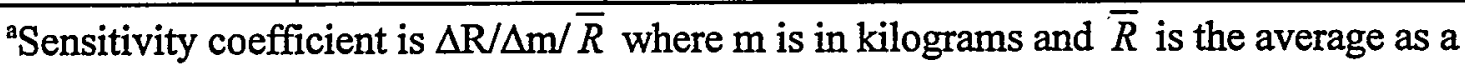
function of mass. 


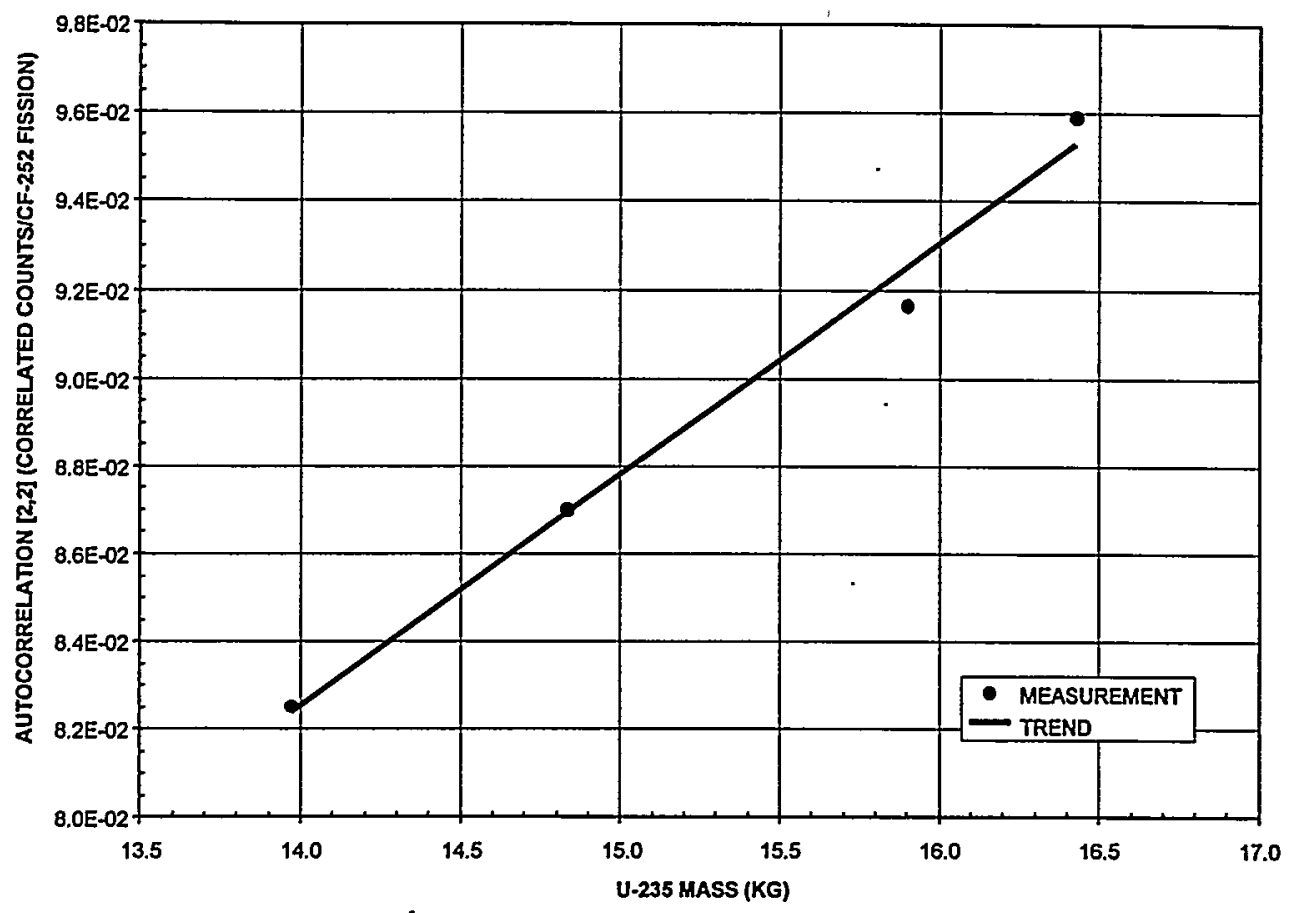

Fig. 6.2. Integral of detector autocorrelation function $[2,2]$ for uranium metal castings as a function of ${ }^{235} \mathrm{U}$ mass.

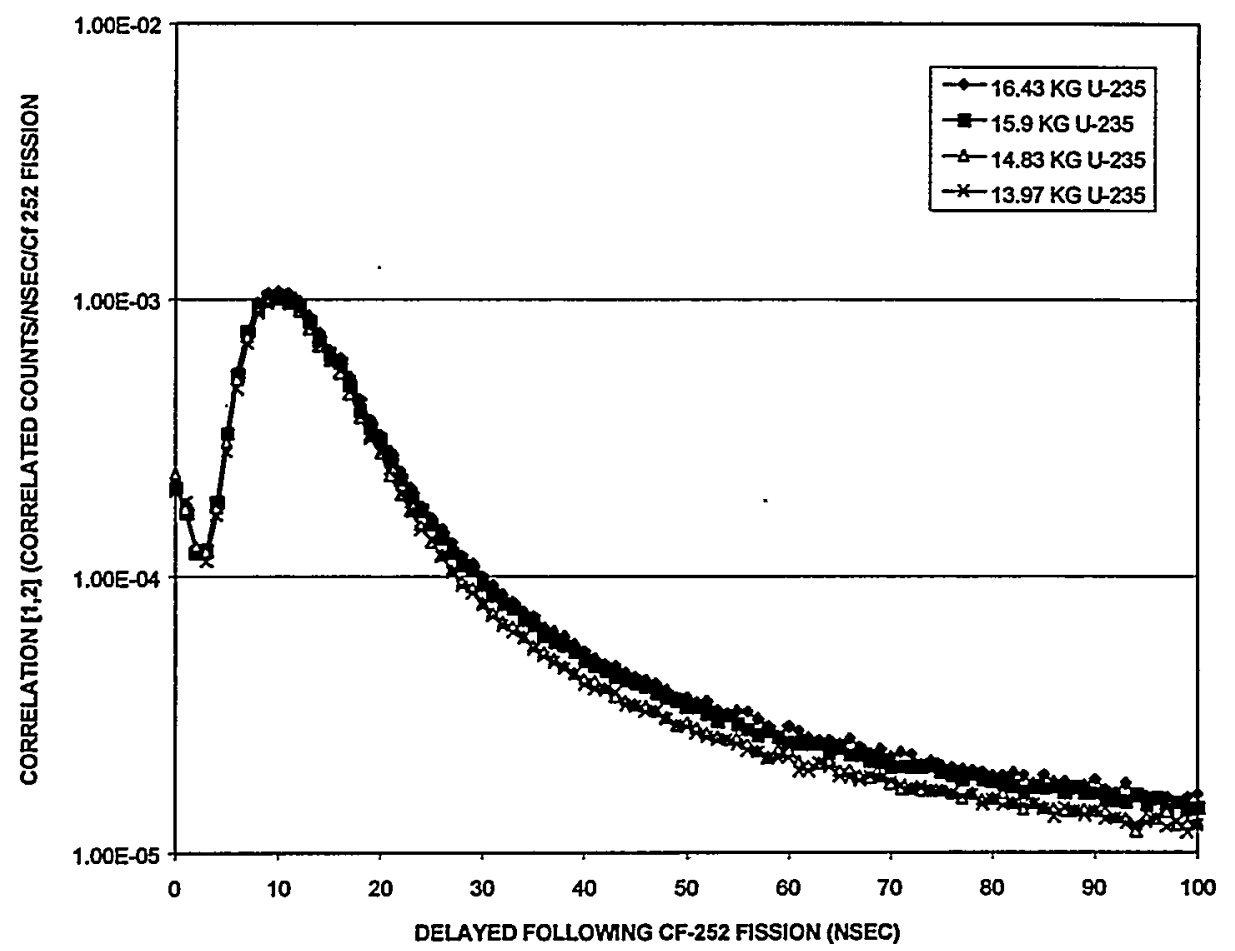

Fig. 6.3. Source-detector cross-correlation $[1,2]$ for uranium metal castings. 
interactions and should not be sensitive to the enrichment. On the other hand the second peak is comprised mainly of transmitted, scattered, and fission produced neutrons that are sensitive by increases for lag times greater than $20 \mathrm{~ns}$. Below $20 \mathrm{~ns}$, the second peak is dominated directly transmitted neutrons and secondary gamma rays that are not strongly dependent on fissile mass. All of the source-detector correlation functions exhibit the same behavior. The integrals of the source-detector correlation functions over time are given in Table 6.2. The integral of the source-detector correlation function changes approximately $12 \%$ from 13.97 to $16.43 \mathrm{~kg}$ of ${ }^{235} \mathrm{U}$.

Table 6.2. Integral of source-detector correlation functions and sensitivity coefficients for annular uranium metal castings

\begin{tabular}{|c|c|c|c|c|}
\hline${ }^{235} \mathrm{U}$ Mass $(\mathrm{kg})$ & $\mathrm{R}_{12}$ & $\mathrm{R}_{13}$ & $\mathrm{R}_{14}$ & $\mathrm{R}_{15}$ \\
\hline 13.97 & $1.57 \mathrm{E}-02$ & $1.58 \mathrm{E}-02$ & $1.42 \mathrm{E}-02$ & $1.42 \mathrm{E}-02$ \\
\hline 14.83 & $1.60 \mathrm{E}-02$ & $1.53 \mathrm{E}-02$ & $1.43 \mathrm{E}-02$ & $1.34 \mathrm{E}-02$ \\
\hline 15.90 & $1.72 \mathrm{E}-02$ & $1.77 \mathrm{E}-02$ & $1.56 \mathrm{E}-02$ & $1.57 \mathrm{E}-02$ \\
\hline 16.43 & $1.79 \mathrm{E}-02$ & $1.80 \mathrm{E}-02$ & $1.61 \mathrm{E}-02$ & $1.60 \mathrm{E}-02$ \\
\hline $\begin{array}{c}\text { Sensitivity } \\
\text { Coefficient }{ }^{\mathrm{a}}\end{array}$ & 0.0549 & 0.0658 & 0.0555 & 0.0629 \\
\hline
\end{tabular}

${ }^{2}$ Sensitivity coefficient is $\Delta \mathrm{R} / \Delta \mathrm{m} / \bar{R}$ where $\mathrm{m}$ is in kilograms and $\bar{R}$ is the average as a function of mass.

A plot of the integral of one of the source-detector cross-correlation functions is given in Fig. 6.4 and is a linear function of ${ }^{235} \mathrm{U}$ mass. The sensitivity of the integral of the autocorrelation function to fissile mass was determined by dividing the slope of a linear fit to the data by the average value of the integral of the autocorrelation function. This sensitivity coefficient is the derivative of the logarithm of the linear fit. The sensitivity coefficients for the integral of the detector autocorrelation functions are approximately 0.06 . The sourcedetector correlation functions have essentially the same sensitivity as the detector autocorrelation functions.

The detector-detector correlation functions are also sensitive to fissile mass as shown in Fig. 6.5. The detector-detector correlation function values increase as fissile mass increases. This is due to the increase in fission in the system as fissile mass increases. The detectordetector correlation functions are symmetric as a function of time. The detector-detector correlation functions were integrated over time and the results are presented in Table 6.3. The integral of the detector-detector cross-correlation function increases approximately $25 \%$ to $27 \%$ as the ${ }^{235} \mathrm{U}$ mass increases from 13.97 to $16.43 \mathrm{~kg}$. A plot of the integral of thedetector-detector cross-correlation function is given in Fig. 6.6 and indicates that this integral varies linearly with fissile mass. The sensitivity coefficient for the integral of the detector-detector correlation function as a function of mass is approximately 0.13 which is twice as large as the sensitivity for the detector autocorrelation and the source-detector correlation. 


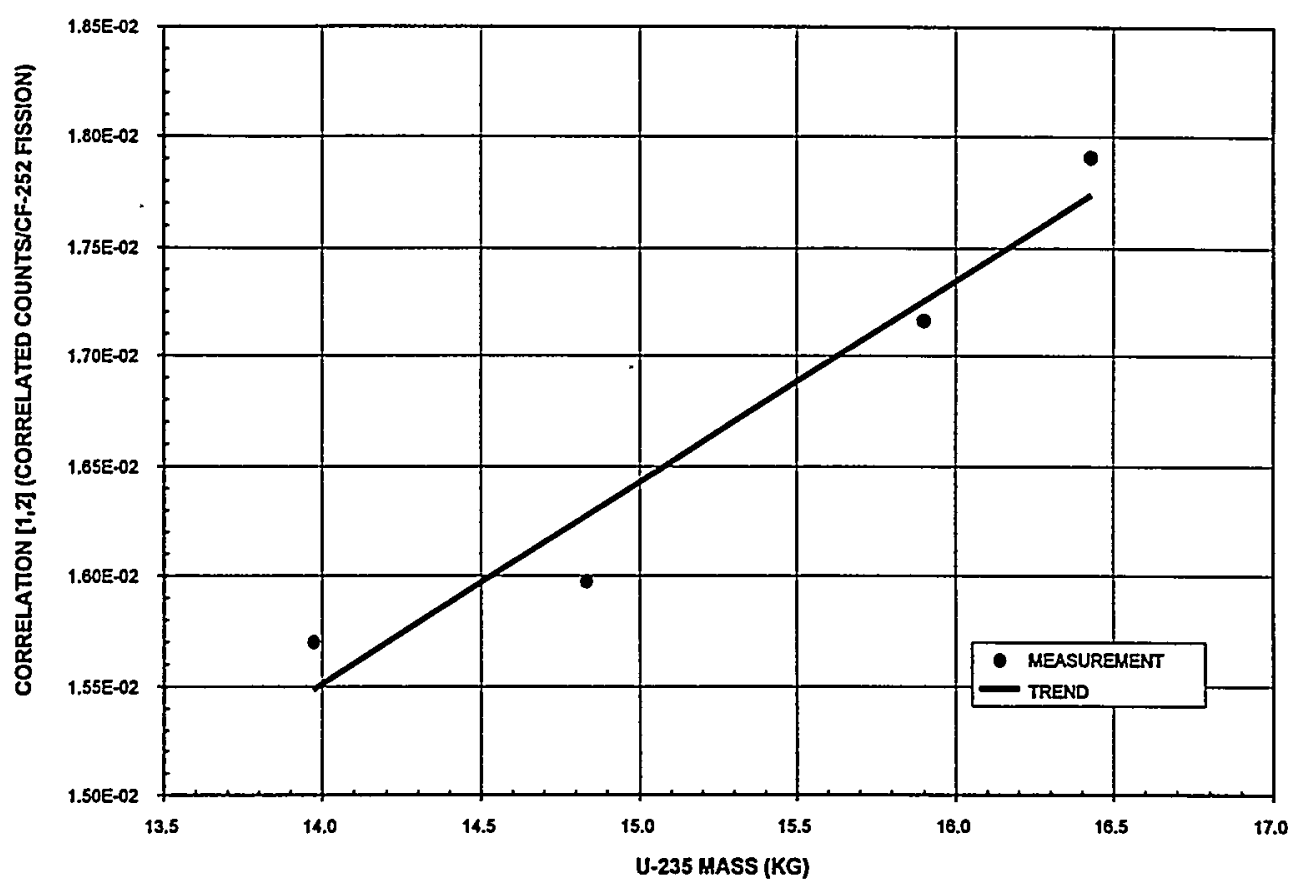

Fig. 6.4. Integral of source-detector cross-correlation $[1,2]$ as a function of ${ }^{235} \mathrm{U}$ mass for uranium metal castings.

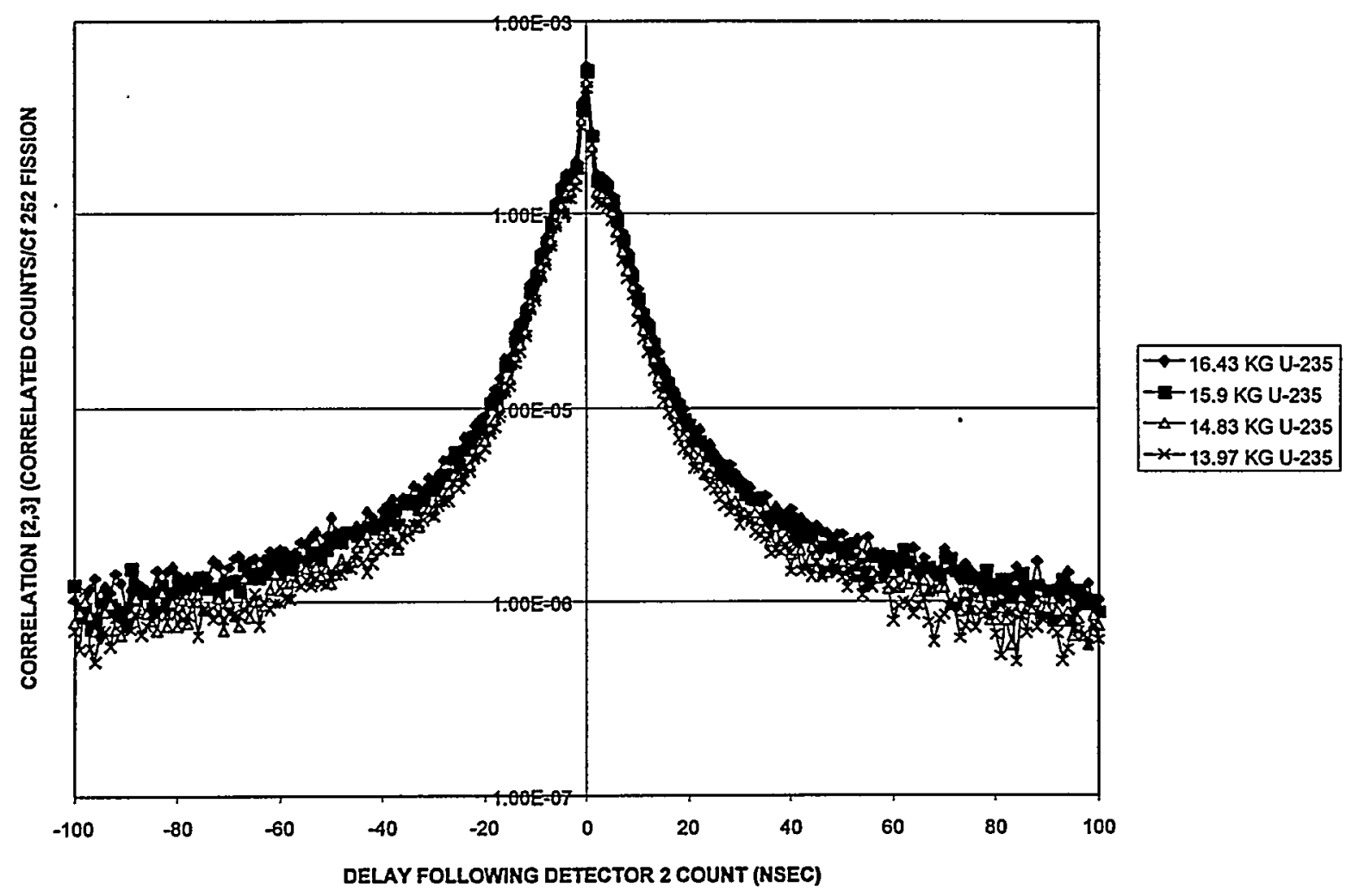

Fig. 6.5. Detector-detector cross-correlation $[2,3]$ for uranium metal castings. 


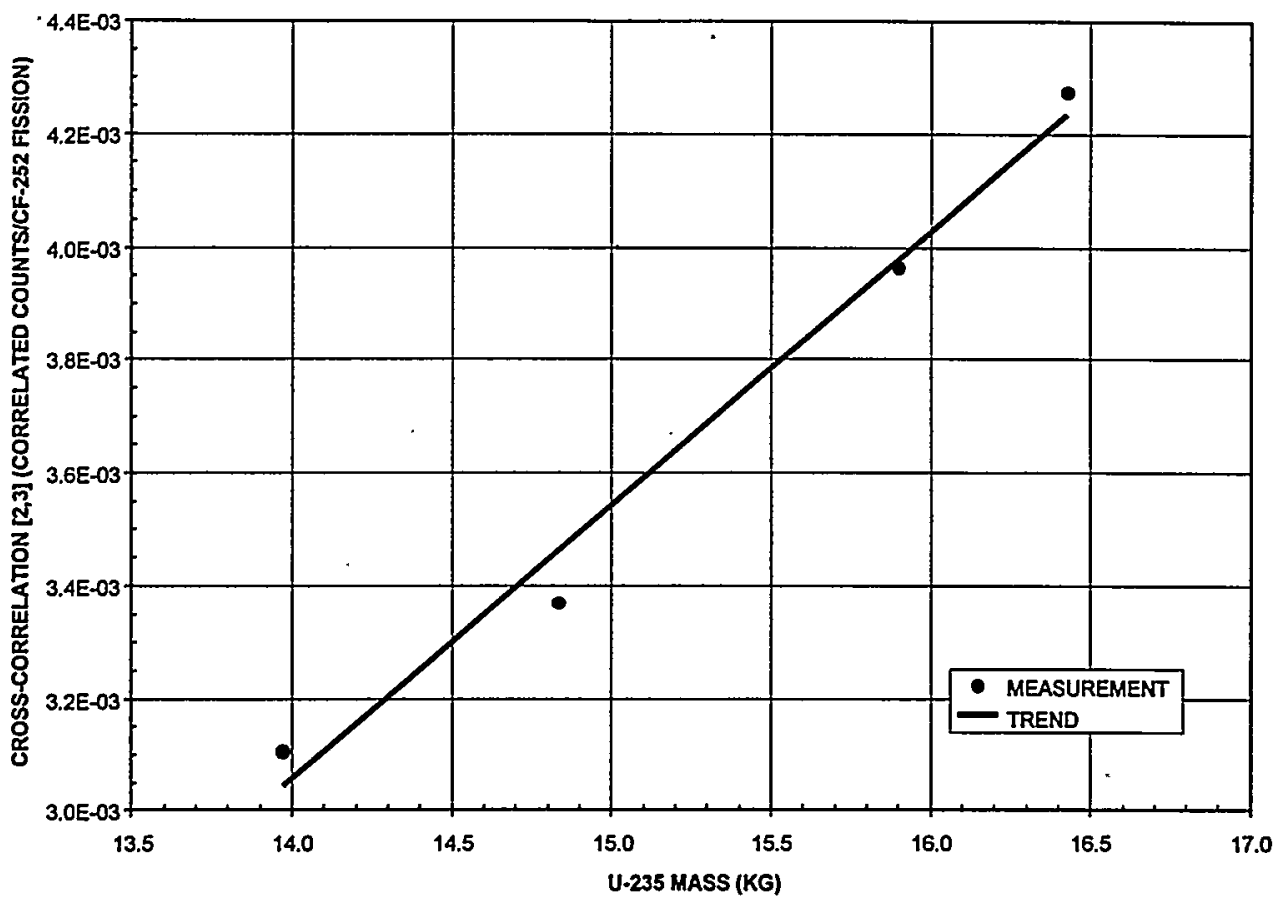

Fig. 6.6. Integral of detector-detector cross-correlation $[2,3]$ vs $^{235} \mathrm{U}$ mass.

Table 6.3. Integral of detector-detector cross-correlation functions and sensitivity coefficients for annular uranium metal castings

\begin{tabular}{|c|c|c|c|c|c|c|}
\hline $\begin{array}{c}{ }^{235} \mathrm{U} \text { mass } \\
(\mathrm{kg})\end{array}$ & $\mathrm{R}_{23}$ & $\mathrm{R}_{24}$ & $\mathrm{R}_{25}$ & $\mathrm{R}_{34}$ & $\mathrm{R}_{35}$ & $\mathrm{R}_{45}$ \\
\hline 13.97 & $3.11 \mathrm{E}-03$ & $2.94 \mathrm{E}-03$ & $2.18 \mathrm{E}-03$ & $2.21 \mathrm{E}-03$ & $2.95 \mathrm{E}-03$ & $2.64 \mathrm{E}-03$ \\
\hline 14.83 & $3.37 \mathrm{E}-03$ & $3.36 \mathrm{E}-03$ & $2.36 \mathrm{E}-03$ & $2.39 \mathrm{E}-03$ & $3.05 \mathrm{E}-03$ & $2.88 \mathrm{E}-03$ \\
\hline 15.90 & $3.97 \mathrm{E}-03$ & $3.64 \mathrm{E}-03$ & $2.80 \mathrm{E}-03$ & $2.83 \mathrm{E}-03$ & $3.79 \mathrm{E}-03$ & $3.30 \mathrm{E}-03$ \\
\hline 16.43 & $4.28 \mathrm{E}-03$ & $3.96 \mathrm{E}-03$ & $3.01 \mathrm{E}-03$ & $3.06 \mathrm{E}-03$ & $3.98 \mathrm{E}-03$ & $3.53 \mathrm{E}-03$ \\
\hline $\begin{array}{c}\text { Sensitivity } \\
\text { Coefficient }\end{array}$ & 0.132 & 0.113 & 0.134 & 0.135 & 0.133 & 0.118 \\
\hline
\end{tabular}

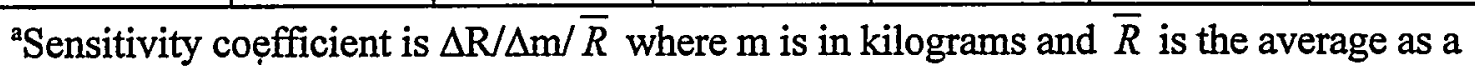
function of mass. 


\subsection{SPECTRAL SIGNATURES}

The auto and cross-correlation functions are Fourier transformed to produce the auto and cross power spectral densities. The frequency spectra are advantageous in that the frequency spectra are independent of accidental correlation except at zero frequency. A comparison of the detector auto power spectral densities for the different mass uranium castings are shown in Fig. 6.7. The auto power spectral densities exhibit large differences between the different uranium metal castings. The auto power spectral densities are essentially constant as functions of frequency because the detector autocorrelation functions are dominated by the relatively large delta function at lag zero. A delta function in the autocorrelation function becomes a constant in the frequency domain. The extrapolated zero frequency values of the detector auto power spectral densities are the same as the integrals of the detector autocorrelation functions that are listed in Table 6.1. The detector auto power spectral densities have the same sensitivity as the integral of the detector autocorrelation functions.

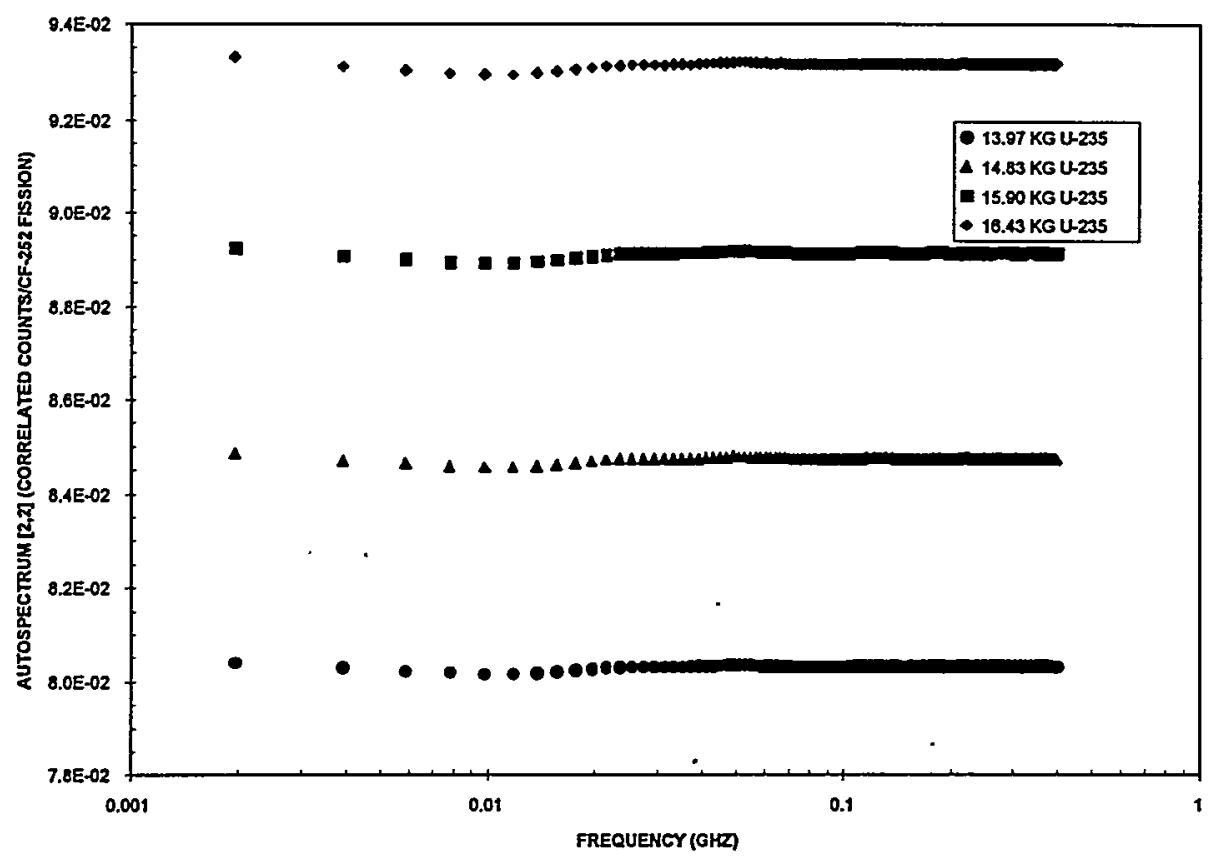

Fig. 6.7. Detector auto power spectral densities $[2,2]$ as a function of frequency for annular uranium metal castings.

The source-detector cross power spectral densities are produced by Fourier transforming the source-detector cross-correlation functions. A comparison of the source-detector cross power spectral densities (12) is given in Fig. 6.8. The source-detector cross power spectral densities can be used to differentiate the uranium metal castings. The source-detector cross power spectral densities exhibit a roll off as a function of frequency that is related to the exponential decrease in the source-detector cross-correlation function as a function of time. The 
extrapolated zero frequency values of the source-detector cross power spectral densities are the same as the integrals of the source-detector cross-correlation functions that are listed in Table 6.2. The source-detector cross power spectral densities have the same sensitivity as the integral of the source-detector cross-correlation functions.

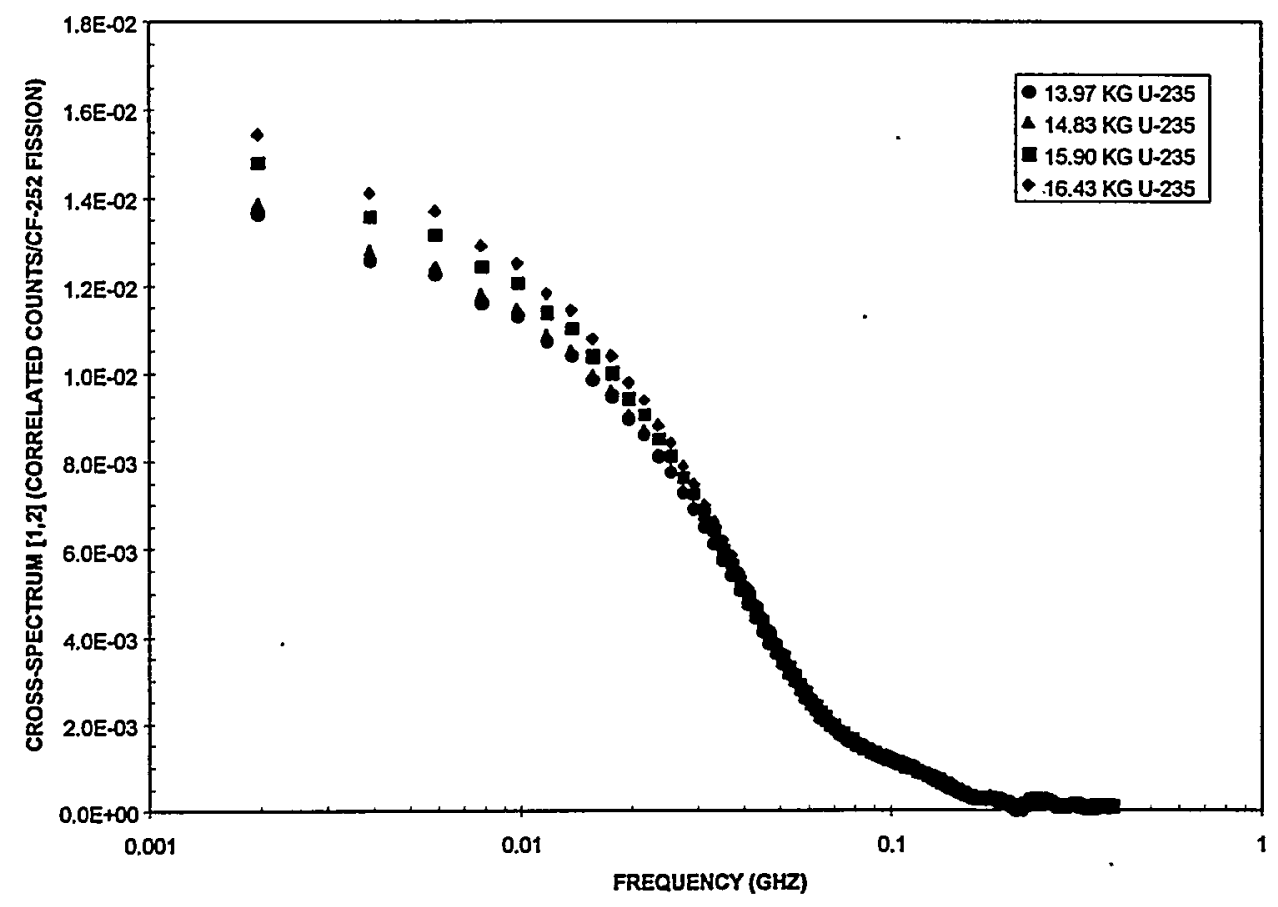

Fig. 6.8. Source-detector cross power spectral densities $[1,2]$ as a function of frequency for annular uranium metal castings.

The detector-detector cross power spectral densities are produced by Fourier transforming the detector-detector cross-correlation functions. A comparison of the detector-detector cross power spectral densities (23) is given in Fig. 6.9. The detector-detector cross power spectral densities can be used to differentiate the uranium metal castings. The roll off as a function of frequency in the detector-detector cross power spectral densities is due to the exponential decrease in the detector-detector cross-correlation functions as a function of time. The extrapolated zero frequency values of the detector-detector cross power spectral densities are the same as the integrals of the detector-detector cross-correlation functions that are listed in Table 6.3. The detector-detector cross power spectral densities have the same sensitivity as the integral of the detector-detector cross-correlation functions. 


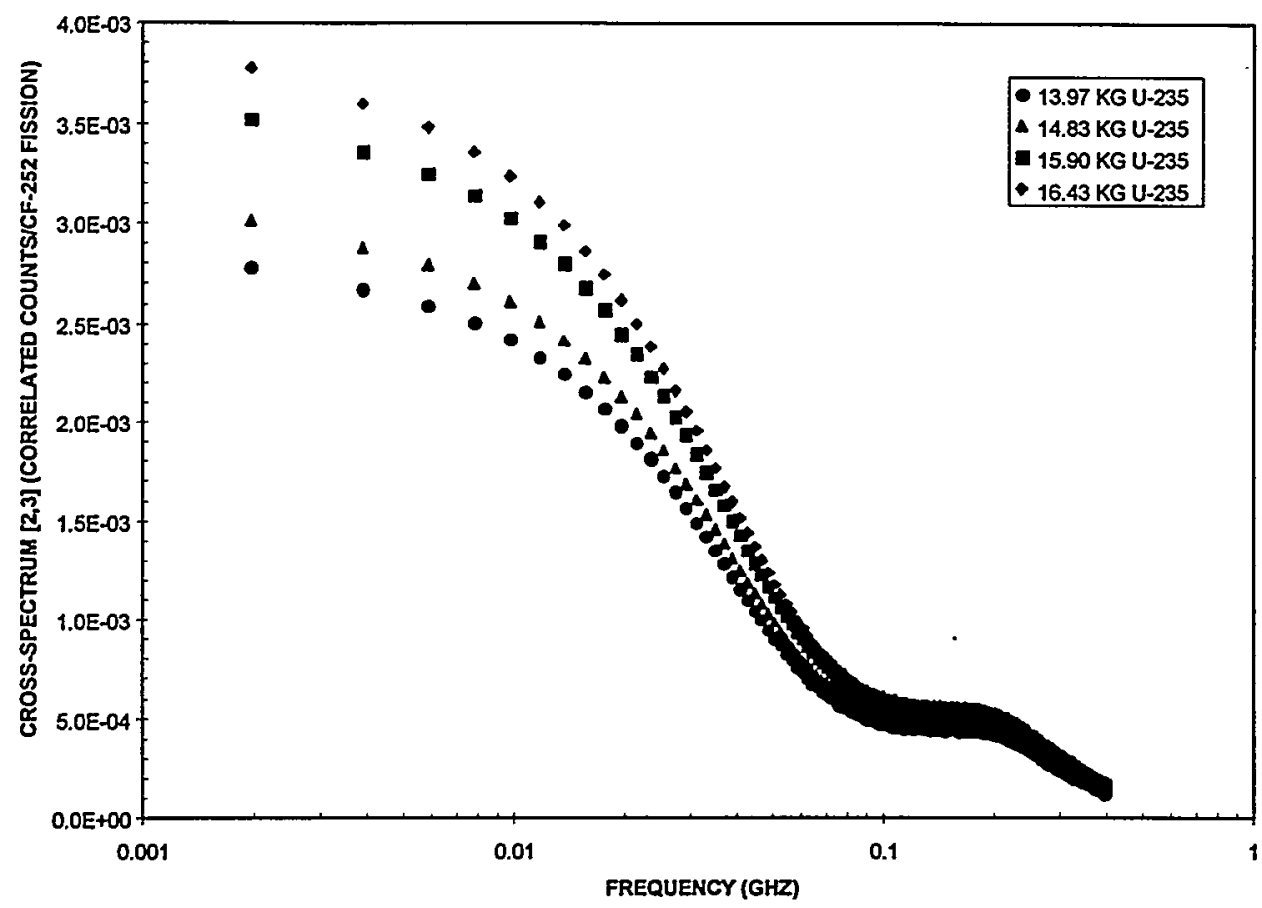

Fig. 6.9. Detector-detector cross power spectral densities [2,3] as a function of frequency for annular uranium metal castings.

Additional frequency spectra are generated from the auto and cross power spectral densities. The coherence is defined as the fraction of common information between two signals. The coherence is expressed mathematically as $\gamma_{i j}^{2}=\left|G_{i j}\right|^{2} / G_{i i j} G_{i j}$ where $G_{i j}$ is the cross power spectral densities between signals $i$ and $j$ and $G_{i i}$ and $G_{i j}$ are the auto power spectral densities of signals $i$ and $j$. Source-detector coherence values and detector-detector coherence values were calculated from the auto and cross power spectral densities. A comparison of the source-detector coherence function (12) is given in Fig. 6.10. The source-detector coherence functions can be used to differentiate the uranium metal castings. The extrapolated low frequency values of the source-detector coherence values are given in Table 6.4 and plotted as a function of ${ }^{235} \mathrm{U}$ mass in Fig. 6.11 . The coherence values for the $14.83 \mathrm{~kg}{ }^{235} \mathrm{U}$ casting deviates from the others. The sensitivity coefficient for the source-detector coherence functions is approximately 0.06 . The coherence values are sensitive to background. 


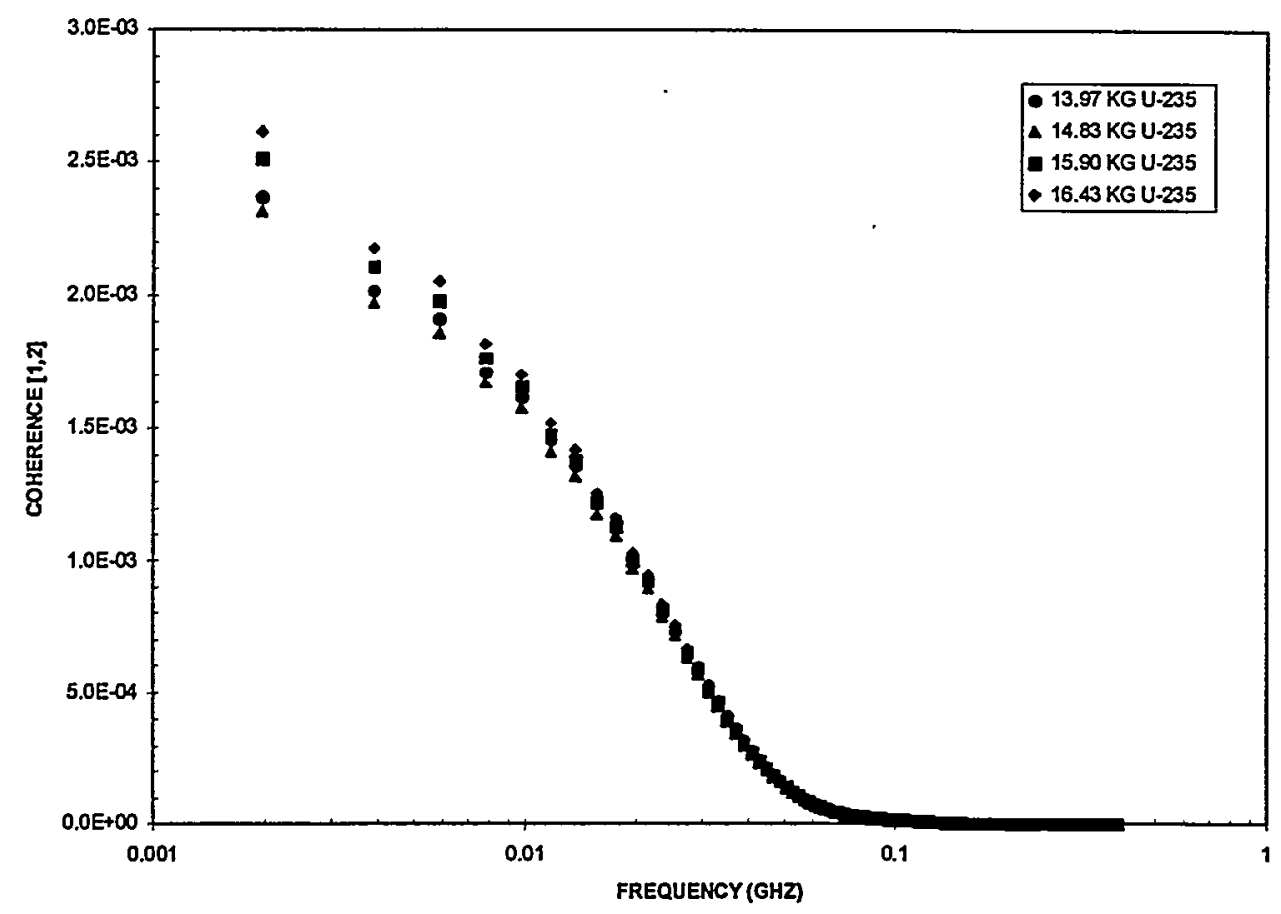

Fig. 6.10. Source-detector coherence $[1,2]$ as a function of frequency for - annular uranium metal castings of varying enrichment of ${ }^{235} \mathrm{U}$ mass.

Table 6.4. Extrapolated low-frequency source-detector coherence values for annular uranium metal castings

\begin{tabular}{|c|c|c|c|c|}
\hline${ }^{235} \mathrm{U}$ mass $(\mathrm{kg})$ & $\gamma_{12}^{2}$ & $\gamma_{13}^{2}$ & $\gamma_{14}^{2}$ & $\gamma_{15}^{2}$ \\
\hline 13.97 & $2.99 \mathrm{E}-03$ & $2.98 \mathrm{E}-03$ & $2.62 \mathrm{E}-03$ & $2.62 \mathrm{E}-03$ \\
\hline 14.83 & $2.93 \mathrm{E}-03$ & $2.77 \mathrm{E}-03$ & $2.53 \mathrm{E}-03$ & $2.33 \mathrm{E}-03$ \\
\hline 15.90 & $3.22 \mathrm{E}-03$ & $3.31 \mathrm{E}-03$ & $2.87 \mathrm{E}-03$ & $2.88 \mathrm{E}-03$ \\
\hline 16.43 & $3.34 \mathrm{E}-03$ & $3.35 \mathrm{E}-03$ & $2.94 \mathrm{E}-03$ & $2.90 \mathrm{E}-03$ \\
\hline $\begin{array}{c}\text { Sensitivity } \\
\text { Coefficient }\end{array}$ & 0.0509 & 0.0642 & 0.0563 & 0.0634 \\
\hline
\end{tabular}

aSensitivity coefficient is $\Delta \mathrm{R} / \Delta \mathrm{m} / \bar{R}$ where $\mathrm{m}$ is in kilograms and $\bar{R}$ is the average as a function of mass. 
The detector-detector coherence functions were calculated from the detector-detector cross power spectral densities and detector auto power spectral densities. The detector-detector coherence function (23) for the different castings is plotted in Fig. 6.12. The detector-detector coherence functions exhibit a linear trend as a function of fissile mass as shown in Fig. 6.13. The extrapolated low frequency values of the detector-detector coherence values are given in Table 6.5. The sensitivity coefficient for the source-detector coherence functions is approximately 0.13 .

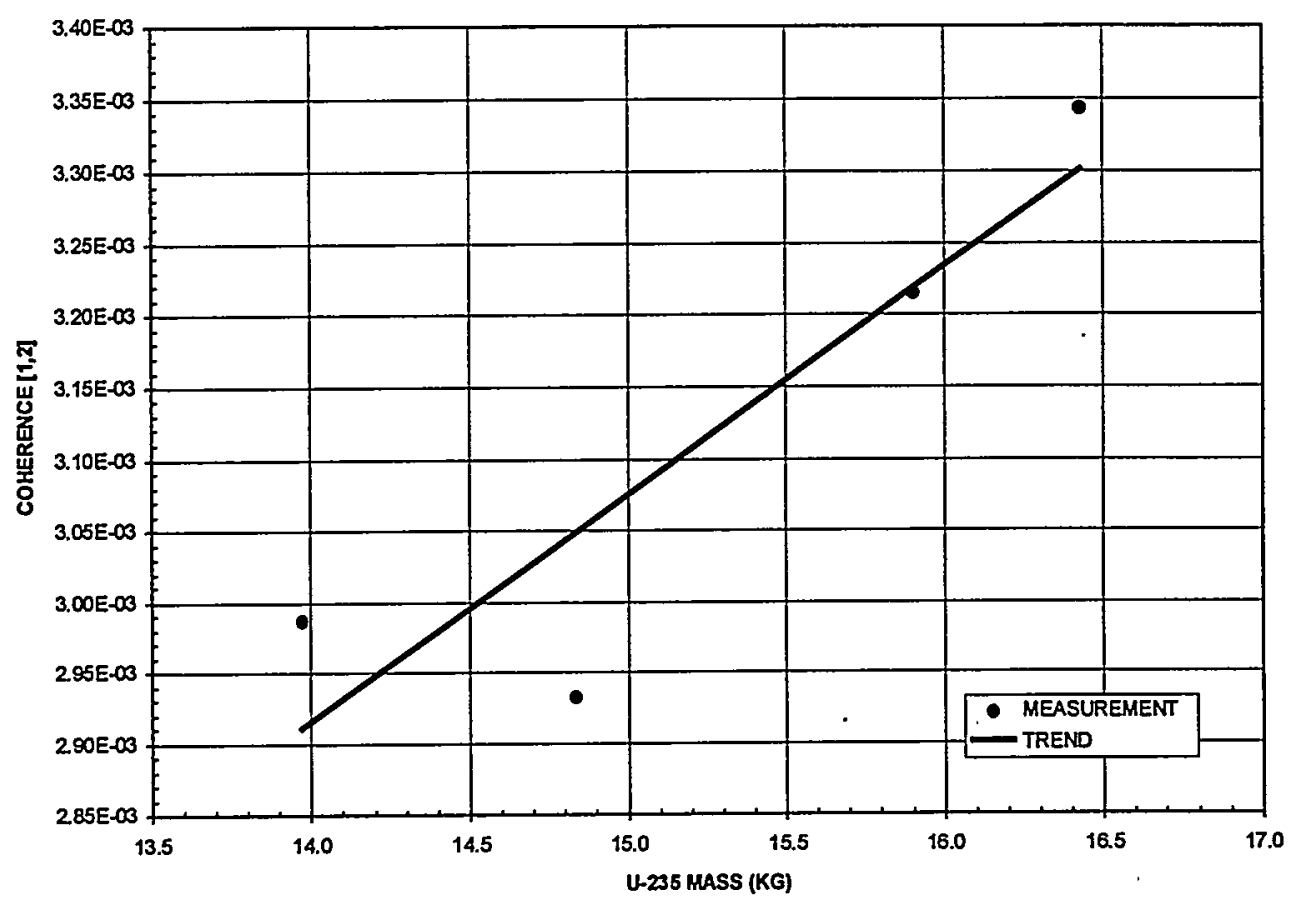

Fig. 6.11. Source-detector coherence $[1,2]$ vs ${ }^{235} \mathrm{U}$ mass of annular metal castings. 
Table 6.5. Extrapolated low-frequency coherence values for annular uranium metal cylinders

\begin{tabular}{|c|c|c|c|c|c|c|}
\hline $\begin{array}{c}{ }^{235} \mathrm{U} \text { mass } \\
(\mathrm{kg})\end{array}$ & $\gamma^{2}{ }_{23}$ & $\gamma_{24}^{2}$ & $\gamma^{2}{ }_{25}$ & $\gamma^{2}{ }_{34}$ & $\gamma^{2}{ }_{35}$ & $\gamma_{45}^{2}$ \\
\hline 13.97 & $1.40 \mathrm{E}-03$ & $1.36 \mathrm{E}-03$ & $7.54 \mathrm{E}-04$ & $7.62 \mathrm{E}-04$ & $1.36 \mathrm{E}-03$ & $1.18 \mathrm{E}-03$ \\
\hline 14.83 & $1.55 \mathrm{E}-03$ & $1.60 \mathrm{E}-03$ & $8.33 \mathrm{E}-04$ & $8.41 \mathrm{E}-04$ & $1.44 \mathrm{E}-03$ & $1.34 \mathrm{E}-03$ \\
\hline 15.90 & $1.82 \mathrm{E}-03$ & $1.70 \mathrm{E}-03$ & $1.00 \mathrm{E}-03$ & $1.01 \mathrm{E}-03$ & $1.79 \mathrm{E}-03$ & $1.50 \mathrm{E}-03$ \\
\hline 16.43 & $1.96 \mathrm{E}-03$ & $1.85 \mathrm{E}-03$ & $1.08 \mathrm{E}-03$ & $1.09 \mathrm{E}-03$ & $1.86 \mathrm{E}-03$ & $1.61 \mathrm{E}-03$ \\
\hline $\begin{array}{c}\text { Sensitivity } \\
\text { Coefficient }^{\mathrm{a}}\end{array}$ & 0.138 & 0.113 & 0.148 & 0.148 & 0.137 & 0.120 \\
\hline
\end{tabular}

aSensitivity coefficient is $\Delta \mathrm{R} / \Delta \mathrm{m} / \bar{R}$ where $\mathrm{m}$ is in kilograms and $\bar{R}$ is the average as a function of mass.

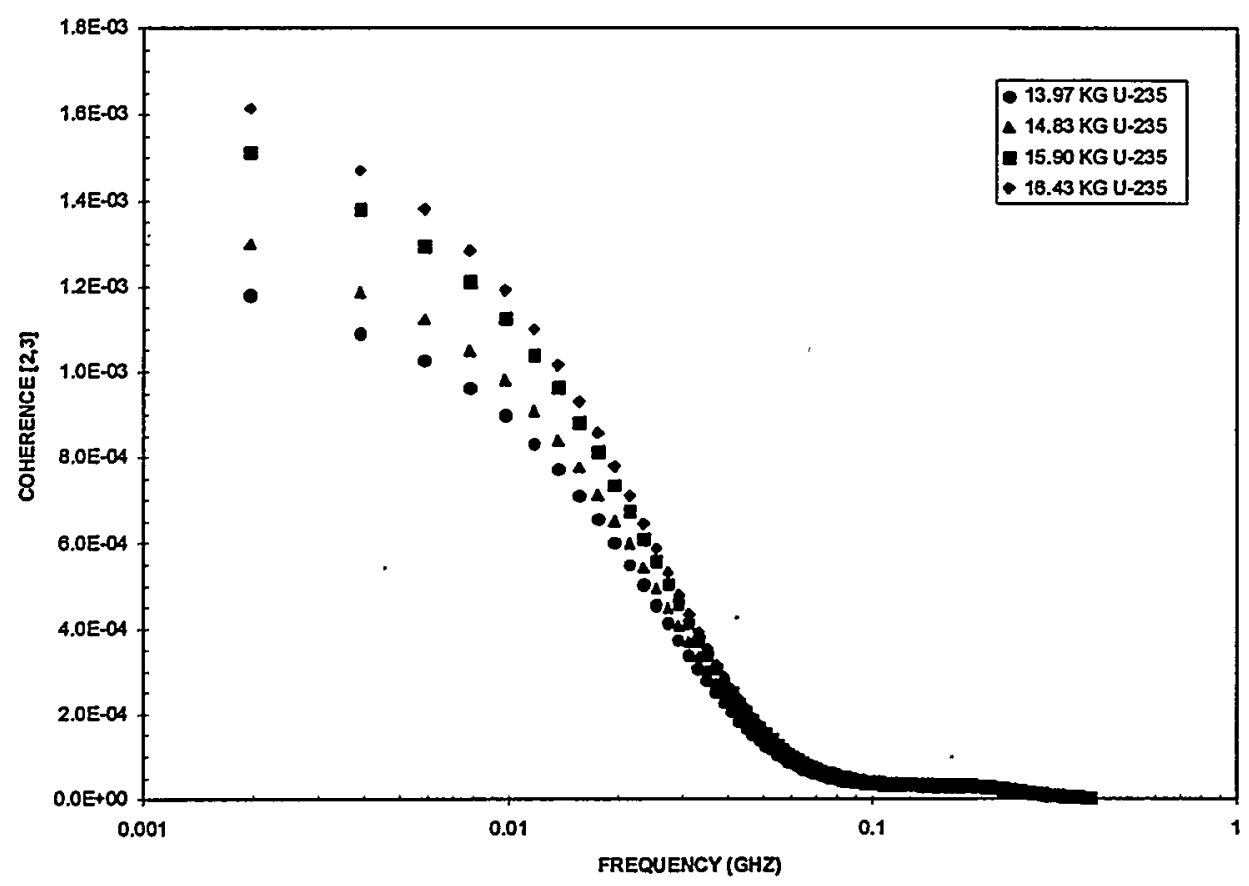

Fig. 6.12. Detector-detector coherence function $[2,3]$ for uranium metal castings. 


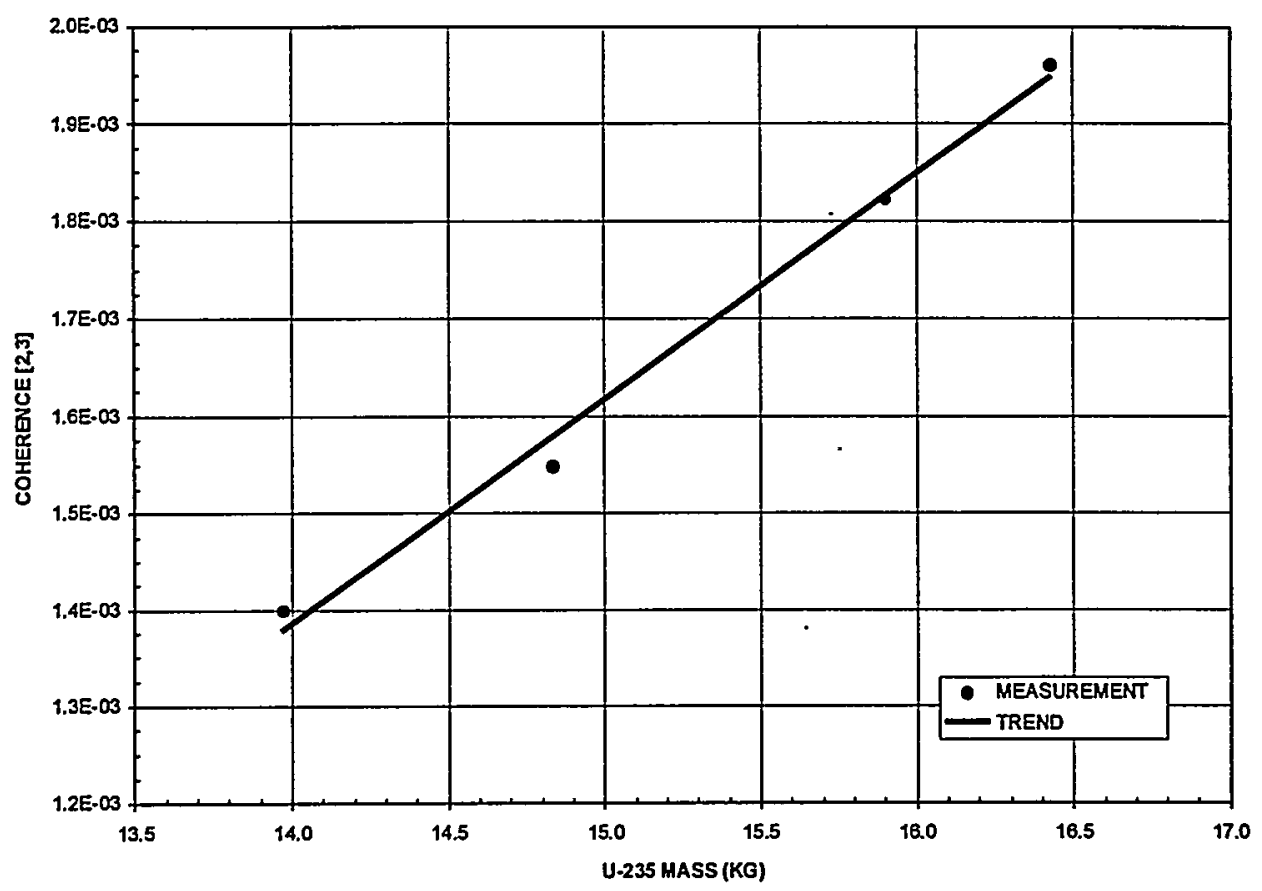

Fig. 6.13. Extrapolated low-frequency detector-detector coherence $[2,3]$ vs ${ }^{235} \mathrm{U}$ mass for uranium metal casting.

\subsection{COUNT PROBABILITY DISTRIBUTION FUNCTION}

The count probability distribution function is determined from the detection events per block. The distribution is determined by measuring the number of times $\mathrm{n}$ counts occur in a block of data in each detector. The total number of detection events for all detectors for each data block is also collected. The block of data consists of 512 time intervals that are $1 \mathrm{~ns}$ wide. The count probability distribution values for the combined detector responses for the different annular uranium metal castings are listed in Table 6.6. As expected the probability for zero detector counts decreases as the mass increase because the average counts per block increases as mass increases. The probability of $1,2,3$, etc. counts per block increases as the fissile mass increases. The difference between the probability of obtaining six counts varies more than a factor of two for an enrichment change from 80 to $93.15 \%$ which corresponds to a mass change from 13.97 to $16.43 \mathrm{~kg}$ of ${ }^{235} \mathrm{U}$. 
Table 6.6. Measured count probability distribution values and average counts per block for annular uranium metal castings

\begin{tabular}{|c|c|c|c|c|}
\hline \multirow{2}{*}{$\begin{array}{c}\text { Count } \\
\text { number }\end{array}$} & \multicolumn{4}{|c|}{${ }^{235} \mathrm{U}$ mass $(\mathrm{kg})$} \\
\hline & 13.97 & 14.83 & 15.90 & 16.43 \\
\hline 0 & $9.375 \mathrm{E}-01^{\mathrm{a}}$ & $9.359 \mathrm{E}-01$ & $9.312 \mathrm{E}-01$ & $9.289 \mathrm{E}-01$ \\
\hline 1 & $5.762 \mathrm{E}-02$ & $5.898 \mathrm{E}-02$ & $6.283 \mathrm{E}-02$ & $6.474 \mathrm{E}-02$ \\
\hline 2 & $4.431 \mathrm{E}-03$ & $4.703 \mathrm{E}-03$ & $5.372 \mathrm{E}-03$ & $5.706 \mathrm{E}-03$ \\
\hline 3 & $3.713 \mathrm{E}-04$ & $4.157 \mathrm{E}-04$ & $5.074 \mathrm{E}-04$ & $5.587 \mathrm{E}-04$ \\
\hline 4 & $3.052 \mathrm{E}-05$ & $3.673 \mathrm{E}-05$ & $4.840 \mathrm{E}-05$ & $5.510 \mathrm{E}-05$ \\
\hline 5 & $2.503 \mathrm{E}-06$ & $3.135 \mathrm{E}-06$ & $4.501 \mathrm{E}-06$ & $5.299 \mathrm{E}-06$ \\
\hline 6 & $2.130 \mathrm{E}-07$ & $3.040 \mathrm{E}-07$ & $4.600 \mathrm{E}-07$ & $5.660 \mathrm{E}-07$ \\
\hline
\end{tabular}

${ }^{\mathrm{a}}$ Obtained from the sum of all four detectors.

The moments of the counts per block are presented in Table 6.7. The combined detector counts per block increase as the fissile mass increases. The average rate per block increases approximately $13 \%$ for a mass increase from $13.97 \mathrm{~kg}$ to $16.43 \mathrm{~kg}{ }^{235} \mathrm{U}$. However, the sensitivity coefficient for the average counts per block is approximately 0.06 and is essentially the same as the detector autocorrelation functions. The sensitivity coefficients for the detector count moments increases as the order of the moments increases.

Table 6.7. Count moments and sensitivity coefficients for annular uranium metal castings

\begin{tabular}{|c|c|c|c|c|}
\hline${ }^{235} \mathrm{U}$ mass $(\mathrm{kg})$ & Counts & Counts $^{2}$ & Counts $^{3}$ & Counts $^{4}$ \\
\hline 13.97 & 0.068 & 0.079 & 0.105 & 0.168 \\
\hline 14.83 & 0.070 & 0.082 & 0.111 & 0.180 \\
\hline 15.90 & 0.075 & 0.090 & 0.123 & 0.206 \\
\hline 16.43 & 0.078 & 0.094 & 0.130 & 0.219 \\
\hline $\begin{array}{c}\text { Sensitivity } \\
\text { Coefficient }\end{array}$ & 0.059 & 0.069 & 0.086 & 0.110 \\
\hline
\end{tabular}

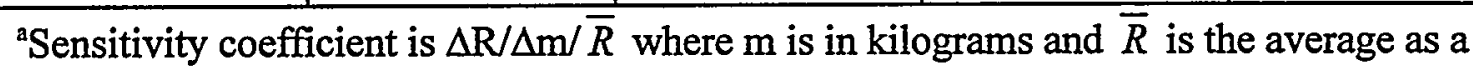
function of mass.

The higher moments for the detector counts are due to the induced fission in the system. This is demonstrated by subtracting the value of the distribution obtained from a strictly Poisson distribution with the same average counts per block. The difference between the measured 
distribution and the Poisson distribution is given in Table 6.8. As expected, the Poisson distribution has a higher probability of zero events than the measured distribution while the measured distribution has higher probabilities than the Poisson distribution for events greater than zero.

Table 6.8. Difference between measured count probability distribution values and Poisson-distributed values

\begin{tabular}{|c|c|c|c|c|}
\hline $\begin{array}{c}\text { Count } \\
\text { number }\end{array}$ & \multicolumn{4}{|c|}{${ }^{235} \mathrm{U}$ mass $(\mathrm{kg})$} \\
\hline & 13.97 & 14.83 & 15.90 & 16.43 \\
\hline 0 & $-6.23 \mathrm{E}-02$ & $-6.40 \mathrm{E}-02$ & $-6.86 \mathrm{E}-02$ & $-7.09 \mathrm{E}-02$ \\
\hline 1 & $5.75 \mathrm{E}-02$ & $5.88 \mathrm{E}-02$ & $6.27 \mathrm{E}-02$ & $6.46 \mathrm{E}-02$ \\
\hline 2 & $4.43 \mathrm{E}-03$ & $4.70 \mathrm{E}-03$ & $5.37 \mathrm{E}-03$ & $5.71 \mathrm{E}-03$ \\
\hline 3 & $3.71 \mathrm{E}-04$ & $4.16 \mathrm{E}-04$ & $5.07 \mathrm{E}-04$ & $5.59 \mathrm{E}-04$ \\
\hline 4 & $3.05 \mathrm{E}-05$ & $3.67 \mathrm{E}-05$ & $4.84 \mathrm{E}-05$ & $5.51 \mathrm{E}-05$ \\
\hline 5 & $2.50 \mathrm{E}-06$ & $3.14 \mathrm{E}-06$ & $4.50 \mathrm{E}-06$ & $5.30 \mathrm{E}-06$ \\
\hline 6 & $2.13 \mathrm{E}-07$ & $3.04 \mathrm{E}-07$ & $4.60 \mathrm{E}-07$ & $5.66 \mathrm{E}-07$ \\
\hline
\end{tabular}




\section{SUMMARY}

These measurements have demonstrated the sensitivity of several of the measured parameters obtained from the source-driven noise analysis measurement. This measurement method can be used to quantify the amount of fissile material for uranium casting components. The detector auto power spectral densities, the source-detector cross power spectral densities, and the detector-detector cross power spectral densities can be related directly to fissile mass. The detector-detector cross power spectral densities are a factor of two more sensitive to fissile mass than the detector auto power spectral densities or the source-detector cross power spectral densities. The frequency spectra also have increased sensitivity over the moments of the count distributions. These measurements were with a very limited number of uranium metal castings and were the first attempt to evaluate this as a method for NDA of the standard Y-12 uranium metal casting. Additional measurements should be performed to evaluate the capability of this NWIS methodology for conventional NDA. Additional measurements can be used to obtain calibration curves and to optimize the measurement configuration for highest sensitivity.

Improved measurement methods with NWIS employing higher order statistics with higher sensitivities to ${ }^{235} \mathrm{U}$ mass have been developed and evaluated theoretically. ${ }^{13}$ The theoretical analysis has confirmed the higher sensitivity to mass and measurements should be performed with these castings using these higher order statistics with their enhanced sensitivity to fissile mass. These higher order correlation measurements with their increased sensitivity to fissile mass should be more useful for quantification of the mass of fissile materials. 


\section{REFERENCES}

1. J. T. Mihalczo, V. K. Paré, G. L. Ragan, M. V. Mathis, and G. C. Tillett, "Determination of Reactivity from Power Spectral Density Measurements with Californium-252," Nucl. Sci. Eng., 66, 29-59 (1978).

2. J. T. Mihalczo and T. E. Valentine, "Calculational Verification and Process Control Applications Utilizing the High Sensitivity of Noise Measurement Parameters to Fissile System Configuration," Nucl. Sci. Eng., 121, 286-300 (1995).

3. T. E. Valentine, J. T. Mihalczo, and P. E. Koehler, "Calculated NWIS Signatures for Enriched Uranium Metal," Proceedings of the $36^{\text {th }}$. Annual Meeting of Institute of Nuclear Materials Management, Palm Desert, California, Vol. XXIV, 388-393 (1995).

4. J. E. Breeding, J. A. Mullens, G. W. Turner, T. E. Valentine, J. A. McEvers, J. T. Mihalczo, and T. A. Gafford, "New NWIS Processor For Fissile System Verification," Institute of Nuclear Materials Management Meeting, Phoenix, Arizona, July 20-24, 1997.

5. J. T. Mihalczo, "The Use of ${ }^{252} \mathrm{Cf}$ as a Randomly Pulsed Neutron Source for Prompt Neutron Decay Measurements," Nucl. Sci. Eng., 41, 296 (1970).

6. J. D. Orndoff, "Prompt Neutron Periods of Metal Critical Assemblies," Nuclear Science and Engineering, Vol. 2, p. 450, 1957.

7. M. J. Paulus, J. T. Mihalczo, T. E. Valentine, J. A. Mullens, J. E. Breeding, T. Uckan, J. K. Mattingly, G. Turner, M. C. Smith, and J. A. McEvers, "A Novel Method for Determining Pulse Counting Circuitry Dead Time Using the Nuclear Weapons Inspection System," Nuclear Science Symposium (1997).

8. J. T. Mihalczo, V. K. Paré, E. D. Blakeman, B. Damiano, T. E. Valentine, L. D. Phillips, R. B. Bonner, D. B. Bopp, T. R. Chilcoat, J. DeClue, E. P. Elliott, G. D. Hackett, N. W. Hill, D. J. Nypaver, L. H. Thacker, W. T. Thomas, J. A. Williams, and R. E. Zumstein, "NWIS Signatures for Confirmatory Measurements with B33 Trainers," Journal of Nuclear Materials Management, Vol. 25, 3, 64-80 (June 1997).

9. J. T. Mihalczo, "New Method for Measurement of the Effective Fraction of Delayed Neutrons from Fission," Nucl. Sci. Eng., 46, 147 (1971).

10. J. T. Mihalczo, W. T. King, and E. D. Blakeman, "Subcriticality Measurements for Coupled Uranium Metal Cylinders Using the ${ }^{252} \mathrm{Cf}$-Source-Driven Neutron Noise Analysis Method," Nucl. Sci. Eng., 95, 1-13 (1987). 
11. T. E. Valentine, J. T. Mihalczo, and J. A. Mullens, "NWIS Signatures For Identification of Weapons Components at the Oak Ridge Y-12 Plant," Institute of Nuclear Materials Management Meeting, Phoenix, Arizona, July 20-24, 1997.

12. M. M. Chiles, J. T. Mihalczo, and C. E. Fowler, "Small, Annular, Double-Contained ${ }^{252} \mathrm{Cf}$ Fission Chamber for Source-Driven Subcriticality Measurements," Institute of Electrical and Electronics Engineers Nuclear Science Symposium, Orlando, Florida, October 27-31, 1992, IEEE Trans. Nucl. Sci., 40, 816-18 (1993).

13. J. K. Mattingly, "High Order Statistical Signatures from Source-Driven Measurements of Subcritical Fissile Systems," Y/LB-15,966, R2, doctoral dissertation, University of Tennessee, Knoxville, May 1998. 
Distribution:

Recipients as designated by the author plus:

Y-12 Plant Records Services (3) 9711-5, MS-8169

[Includes 2 copies for. OSTI and I copy for Central Files]

Note: This distribution page should not be included in the copy of your document (abstract, visuals, article, etc.) submitted to a journal or technical society. 